\title{
El Arbitraje Cooperativo en la Legislación Española
}

\author{
Jaume Martí Miravalls \\ Investigador del Departamento de Derecho Mercantil «Manuel Broseta Pont», \\ de la Universitat de València
}

\begin{abstract}
Sumario: I. Introducción.-II. La evolución del arbitraje cooperativo en la legislación cooperativa estatal.- - III. El arbitraje cooperativo en la ley estatal 27/1999, de 16 de julio, de cooperativas.-IV. El cooperativismo y la legislación arbitral.- $\mathrm{V}$. Algunas reflexiones sobre convenio arbitral y conflictos cooperativos.-VI. El arbitraje cooperativo en la legislación autonómica. VI.1. País Vasco. VI.2. Cataluña. VI.3. Comunidad Valenciana. VI.4. Extremadura. VI.5. Galicia. VI.6. El procedimiento arbitral: cuestiones comunes.VII. Algunas reflexiones sobre la conciliación cooperativa en la legislación autonómica.-VIII. Bibliografía.
\end{abstract}

\section{Introducción}

El presente estudio tiene por objeto el análisis del arbitraje cooperativo como vía alternativa de resolución de conflictos. La investigación podría dividirse en dos bloques: en el primero se analizan las cuestiones polémicas relacionadas con la figura del arbitraje cooperativo. Así, partiendo de unas breves nociones sobre el arbitraje cooperativo se procede al análisis de la figura, tanto en la legislación cooperativa estatal como en la legislación arbitral, finalizando con la investigación sobre la relación entre convenio arbitral y conflictos cooperativos - por ser éste uno de los puntos más controvertidos-. Por su parte, en el segundo bloque se desarrolla el actual régimen legal del arbitraje cooperativo, que es básicamente autonómico. Partiendo del análisis del arbitraje cooperativo en la vigente legislación autonómica se profundiza individualmente en la evolución histórica de la legislación cooperativa de las Comunidades Autónomas con institución pública representativa del movimiento cooperativo y desarrollo normativo del arbitraje cooperativo. Finalmente, por su relación con la figura analizada como medio de resolución de conflictos previsto en las distintas legislaciones cooperativas autonómicas, se realizan algunos apuntes sobre las principales cuestiones polémicas que la actual regulación de la conciliación cooperativa plantea. 
El arbitraje es un medio alternativo de resolución de conflictos. Si en algún campo tiene sentido la resolución alternativa de conflictos es en el movimiento cooperativo ya que éste siempre ha buscado la puesta en común de las diferentes potencialidades de sus miembros ${ }^{1}$. El arbitraje es una institución especialmente apta para solucionar los conflictos de intereses que pueden surgir en el seno de una cooperativa, tanto por su naturaleza como por la dinámica interna de las sociedades cooperativas, que requieren de soluciones internas pacíficas y alternativas a las derivadas de la jurisdicción ordinaria. Así entendido, el arbitraje cooperativo se presenta como una institución que soluciona particularmente, entre los propios cooperativistas, las diferencias que puedan surgir en la actividad cotidiana de la cooperativa.

\section{La evolución del arbitraje cooperativo en la legislación cooperativa estatal}

Analizando la evolución normativa del arbitraje cooperativo como institución, se observa como ni en la Ley de Cooperativas de 19312, ni en su Reglamento ${ }^{3}$ — normas de la Segunda República-, se produce ninguna alusión al arbitraje cooperativo. Tampoco en la Ley de Cooperativas de 27 de octubre de 1938 — dictada para la zona nacional durante la guerra civil-, ni en la Ley de Cooperativas de 2 de enero de 1942 — finalizada la guerra civil- se encuentra ninguna referencia legal al arbitraje cooperativo.

Ahora bien, en el artículo 57 de la Ley de 1942 se dispuso que la Obra Sindical de Cooperación - que era la encargada de promover, dirigir, tutelar y vigilar el régimen cooperativo ${ }^{4}$ - estaría asesorada por un Consejo Superior, cuya organización y funcionamiento se determinarían en Reglamento. Fue precisamente en ese Reglamento, Decreto de 11 de noviembre de 1943 para la aplicación de la Ley de Cooperativas, donde se recogió el primer reconocimiento legal del arbitraje cooperativo. Concretamente, el artículo 82.3 del Reglamento fue el

Merino Hernández, S. Manual de Arbitraje Cooperativo Vasco, CSCE, 2001, pág. 76.

2 Primero, Decreto-ley de 4 de julio de 1931, que fue elevado a Ley el 9 de septiembre del mismo año.

3 Decreto de 20 de octubre de 1931.

4 Artículos 54 y 55 de la Ley de Cooperativas de 2 de enero de 1942. 
encargado de atribuir competencia al Consejo Superior de la Obra Sindical de Cooperación ${ }^{5}$ sobre "el arbitraje de las cuestiones que eleven voluntariamente las Cooperativas y Uniones». En base a este único precepto reglamentario el Consejo Superior de la Obra Sindical de Cooperación comenzó a dictar laudos resolviendo conflictos entre cooperativas, y entre éstas y sus socios, e incluso entre Cooperativas y sus Uniones ${ }^{6}$.

El problema surgió cuando en el año 1953 se aprobó la Ley de Arbitraje de Derecho Privado, de 22 de diciembre (LADP). Esta norma presentaba serios inconvenientes frente al sistema instaurado en el arbitraje cooperativo. Por un lado, eliminaba la eficacia directa de los convenios arbitrales, al distinguir entre cláusula compromisoria -0 contrato preliminar de arbitraje, cuya finalidad era preparar el arbitraje, no instituirlo- y compromiso - que exigía posterior acuerdo formal cuando la controversia ya estuviera determinada-. Ello suponía privar de eficacia directa los compromisos de arbitraje pactados con carácter previo a que se produjese el conflicto de intereses - por ejemplo, cuando la sumisión al arbitraje se recogía en los Estatutos de la cooperativa-. Por otro lado, la norma prohibía los pactos de cesión a un tercero de la facultad de nombrar árbitros ${ }^{7}$, lo que acababa directamente con cualquier arbitraje institucional, que era y es el propio del ámbito cooperativo ${ }^{8}$. Especialmente gráfica fue la Sentencia del Tribunal Supremo de 3 de febrero de 1986 (RJ 1986/411) — vigente la LADP_- en la que se denegó la excepción de incompetencia de la jurisdicción ordinaria porque no se comprendía perfeccionado el compromiso arbitral al no haberse formalizado judicialmente el arbitraje, pese a la cláusula de sometimiento establecida en los Estatutos de la cooperativa - Fundamento Jurídico 2. - .

Ante esta situación el Consejo Superior de Cooperación optó por la solución más cómoda, cual fue rechazar el conocimiento de cual-

5 Que era el más alto organismo asesor de la Obra Sindical de Cooperación, artículo 80 del Reglamento de 11 de noviembre de 1943.

6 Muñoz VIDAL, A. El arbitraje cooperativo, Caja rural provincial de Murcia, 1978, págs. 25 y ss. La función arbitral de este Consejo Superior de la Obra Sindical de Cooperación respondía a los principios corporativos y pactistas propios de la dictadura. Véase, TRUJILlo DíEZ, I.J. «El arbitraje cooperativo. Régimen legal y otras cuestiones» en Estudios sobre economía social y derecho cooperativo, 2000, pág. 158; Polo, A. "Misión y sentido de la nueva Ley de Cooperación», RDP, 1942, págs. 30 y ss.

7 Artículo 22 LADP.

8 En este sentido, Trujllo Díez, I.J. El arbitraje cooperativo..., cit., págs. 158 y 159. 
quier tipo de arbitraje que se le solicitase, argumentando la falta de jurisdicción que le imponía la LADP. Esta situación fue criticada por la doctrina9 ${ }^{9}$, puesto que se hubiera podido salvar por la vía del artículo 1.2 de la propia LADP, que establecía que los arbitrajes ordenados en prescripciones de Derecho Público, sean internacionales, corporativos, sindicales o de cualquier otra índole, continuarían sometidos a las disposiciones por que se regían. En consecuencia, y dado el periodo histórico en el que se encontraba, el arbitraje cooperativo podía considerarse incluido tanto dentro del ámbito corporativo como en el sindical, quedando, por tanto, excluido del régimen legal de la LADP.

El sistema arbitral cooperativo había quedado paralizado por motivos ajenos al propio movimiento cooperativo. Sin embargo, éste era consciente de la necesidad de volver a armarlo, y así en la Asamblea Nacional de Cooperativas, celebrada en Madrid del 27 al 30 de noviembre de 1961 —donde se reunían los grandes expertos del movimiento cooperativo- se aprobó un documento sin valor jurídico, pero con gran autoridad científica, que pretendía ser las «bases del futuro ordenamiento jurídico de la cooperación y régimen fiscal de las cooperativas», el cuál en su base XXII disponía que «corresponderá al Consejo Superior de Cooperativas... arbitrar las cuestiones que se planteen entre las cooperativas y sus asociados...» y que "la Ley regulará el ejercicio de la función de arbitraje del Consejo en términos que aseguren a sus resoluciones fuerza de obligar». Se observa, pues, cómo el movimiento cooperativo no se había olvidado del arbitraje cooperativo institucional.

En esta situación se llega al año 1971, en el que con la aprobación del Reglamento de Cooperación, Decreto 2396/1971 de 13 de agosto, el arbitraje cooperativo se vio nuevamente fortalecido ${ }^{10}$, en la medida en que se superaban los problemas que había planteado la LADP. En la Exposición de Motivos del Reglamento se hablaba de "revitalizar» las funciones del Consejo Superior de la Obra Sindical de Cooperación. Fue el artículo 83 del Reglamento el que nuevamente atribuye legalmente al Consejo Superior la capacidad de arbitrar y

9 Vicent ChuliÁ, F. «Análisis crítico del nuevo Reglamento de Cooperación», RDM, núm. 125, 1972, pág. 517.

10 Aunque el profesor VICENT CHULIÁ consideró que el Reglamento no restableció o rehabilitó la función arbitral del Consejo, sino que se limitó a aclarar su regulación legal y a desarrollarla al margen de la Ley sobre arbitraje privado. VICENT CHULIÁ, F. Análisis crítico..., cit., pág. 518. 
resolver litigios sobre problemas cooperativos. El precepto, que tenía como rúbrica la «función arbitral del Consejo», establecía que «1. El Consejo Superior arbitrará en las cuestiones que se planteen entre las entidades cooperativas o entre éstas y sus socios cuando ambas partes soliciten este arbitraje o estén obligadas a ello por sus Estatutos. 2. La función arbitral conferida al Consejo Superior de la Obra Sindical de Cooperación está excluida de la LADP y sus decisiones participarán de la naturaleza de los acuerdos transaccionales. Contra ellos no cabrá recurso alguno en la vía sindical ni administrativa. 3. Los afectados por dichas decisiones arbitrales podrán pedir su cumplimiento ante los Juzgados y Tribunales competentes de la jurisdicción ordinaria y sólo podrán quedar sin efecto por las causas de invalidación de los contratos. 4. El Consejo Superior podrá rechazar el ejercicio de la función de arbitraje cuanto la cuestión sometida a su conocimiento no sea específicamente cooperativa». Este breve pero importante artículo marcaba las bases del relanzamiento en el marco legal del arbitraje cooperativo, siendo completado con el Reglamento de actuación del Consejo Superior y de los Consejos Provinciales de Cooperación, aprobado por Resolución de la Obra Sindical de Cooperación de 27 de febrero de 1973, el cual se encargaba de recoger el régimen procedimental del arbitraje cooperativo.

En el año 1974 se aprueba una nueva Ley General de Cooperativas, Ley 52/1974, de 19 de diciembre, en la que se disuelve el Consejo Superior de la Obra Sindical de Cooperación —Disposición Transitoria 5 . $^{\text {- }}$. Este es sustituido en sus funciones por la Federación Nacional de Cooperativas, que pasa a denominarse Confederación Española de Cooperativas —artículo 56.1 LGC-, a la que se le atribuyen las funciones que venía desarrollando el Consejo Superior. En concreto en el artículo 56.2.c) se le otorga la facultad de «arbitrar en las cuestiones litigiosas que se susciten entre las entidades cooperativas, o entre éstas y sus miembros, cuando ambas partes soliciten este arbitraje o estén obligadas a ello a tenor de sus Estatutos. Las normas de aplicación y desarrollo regularán este arbitraje». Esta fue la primera vez que una Ley de Cooperativas se refiere expresamente a la institución del arbitraje cooperativo. La sustitución efectiva del Consejo Superior se produjo cuando se aprobaron los Estatutos de la Federación Nacional de Cooperativas, a propuesta del propio Consejo Superior, por la Orden del Ministerio de Relaciones Sindicales de 21 de julio de 1975, la cuál dedicaba los artículos 92 a 96 a desarrollar lo dispuesto en el artículo 56.2.c) de la Ley 52/1974 —el artículo 92 recogía la 
competencia de arbitrar y establecía los requisitos que debían concurrir; mientras que los artículos 93 a 96 recogían las reglas de procedimiento-.

Finalizada la dictadura, mediante el Real Decreto 2508/1977, de 17 de junio, se desmonta el sistema del asociacionismo cooperativo del régimen franquista, recomponiéndose en Uniones, Federaciones y la Confederación Española de Cooperativas, a las que se les atribuye autónomamente la función arbitral que hasta entonces le correspondía a la Federación Nacional de Cooperativas. El 16 de noviembre de 1978 se aprueba un nuevo Reglamento de Cooperativas en el que voluntariamente se opta por no regular el arbitraje cooperativo ${ }^{11}$, dando simplemente una solución provisional, como fue incluir en sus «tablas de vigencias» la Orden Ministerial de Relaciones Sindicales de 1975, en tanto se formaba la nueva organización asociacional cooperativa. En principio, en el Anteproyecto de Reglamento de cooperativas - que se estaba discutiendo en el año 1975- aparecía expresamente recogido el régimen procedimental del arbitraje cooperativo ${ }^{12}$, pero, como consecuencia de todos los cambios habidos en ese periodo, finalmente se opta por la no regulación del mismo, bajo la convicción de que se trataba de una materia autónoma que debía ser regulada por el propio movimiento cooperativo ${ }^{13}$.

Con la Ley 3/1987, de 2 de abril, General de Cooperativas, se deroga la anterior Ley de 14 de diciembre de 1974, introduciéndose un minucioso régimen jurídico sobre este tipo sociedades en relación a las regulaciones anteriores. Pese a la mayor regulación de las sociedades cooperativas, la convicción de que el arbitraje cooperativo se trataba de una materia autónoma que debía ser regulada por el propio movimiento cooperativo, tuvo como consecuencia que, pese a que en el texto legal se recogieran algunas referencias al arbitraje ${ }^{14}$, este sistema fue más aparente que real.

La norma atribuía funciones arbitrales y de conciliación al Consejo Superior del Cooperativismo —artículos 162 y 163-, si bien ello no

11 Aunque sí recoge la existencia del arbitraje en tres de sus preceptos: artículos 47.2.b; 73.2 y 114.2 .

12 MUÑOz VIDAL, A. El arbitraje..., cit., págs. 34 y 35.

13 Trujlllo Díez, I.J. El arbitraje cooperativo..., cit., pág. 161.

14 La norma también establecía que una de las funciones de la Uniones, Federaciones y Confederaciones era la de "ejercer la conciliación en los conflictos surgidos entre las Sociedades Cooperativas que asocien o entre éstas y sus socios», artículo 161.1.a). 
tuvo tiempo —ni había voluntad- para ponerse en funcionamiento. Estos preceptos fueron derogados, junto con la extinción del propio Consejo Superior, por el artículo 98.5 de la Ley 31/1990, de 27 de diciembre, de Presupuestos Generales del Estado para 199115. De esta manera la postura abstencionista que el legislador estatal había mantenido durante los primeros años de la democracia se va a imponer, manteniéndose así hasta el día de hoy, dado que en esta línea se encuentra también la actual Ley 27/1999, de 16 de julio, de Cooperativas, que tampoco crea ningún tipo particular de arbitraje institucional.

Pese a ello, no sería correcto considerar que el arbitraje cooperativo haya sido una institución muerta durante la etapa democrática, sino todo lo contrario, es donde mayor esplendor esta viviendo, debido a que la postura mantenida por el legislador estatal no está siendo mayoritariamente seguida por los legisladores autonómicos, que son los auténticos artífices de que el arbitraje cooperativo — con todas sus ventajas - no sólo evolucione y se consolide, sino también se promocione y perfeccione con el desarrollo normativo del mismo, dotando al sistema de una mayor seguridad jurídica.

\section{El Arbitraje Cooperativo en la Ley Estatal 27/1999, de 16 de julio, de Cooperativas}

La Ley 27/1999, de 16 de julio, de cooperativas (en adelante LC), ha renunciado a crear cualquier tipo particular de arbitraje administrativo, aunque sí que prevé unas breves notas sobre el arbitraje cooperativo. Cuando el legislador nacional decide aprobar la nueva LC era completamente consciente de que no deseaba instaurar una institución administrativa central encargada del movimiento cooperativo nacional al estilo de la Ley 3/1987, de 2 de abril. Pero también era consciente de que el arbitraje cooperativo era una figura que no podía olvidar, aunque no crease una institución concreta encargada de llevarlo en práctica, porque a nivel autonómico era algo tradicional, e in-

15 Ello ha llevado a la doctrina a considerar que el Consejo Superior del Cooperativismo era un organismo «non nato», ya que nunca se constituyó. VILLALOBos/DelibES/Alonso, Comunidades de bienes, cooperativas y otras formas de empresas, Consejo General del Notariado, 1996, pág. 1228. En esta misma línea, se ha dicho que los artículos 162 y 163 de la Ley de Cooperativas de 1987 eran «letra muerta». BuITRON ANDRADE, "Evolución de la figura del Consejo Superior de Cooperativas en la legislación cooperativa española» en Anuario de Estudios Cooperativos, 1999, pág. 211. 
cluso en algunos casos consolidado o en fase de consolidación. En consecuencia, su aportación debía ser algo que no molestase a los sistemas autonómicos ya existentes. A ello se une la doctrina que - para el arbitraje societario en general- emanaba de las —en ese momento recientes - resoluciones de la DGRN de 19 de febrero de 1998 (RJ 1118/1998) y del TS de 18 de abril de 1998 (RJ 2984/1998). Ante esta situación, se optó por la solución más general posible, como fue refundir a grandes rasgos las reglas generales que tradicionalmente existían sobre arbitraje cooperativo a nivel autonómico y las recientes reglas que para el arbitraje societario acababan de instaurar las resoluciones de la DGRN y del TS de 1998.

La Ley 27/1999, de Cooperativas, dedica su Disposición Adicional $10 .^{a}$ a marcar una serie de pautas, no demasiado acertadas ${ }^{16}$, relativas al arbitraje cooperativo. El precepto establece que «1. Las discrepancias o controversias que pueden plantearse en las cooperativas, entre el Consejo Rector o los apoderados, el Comité de Recursos y los socios, incluso en el periodo de liquidación, podrán someterse a arbitraje de derecho regulado por la Ley 36/1988, de 5 de diciembre; no obstante, si la disputa afectase principalmente a los principios cooperativos podrá acudirse al arbitraje de equidad. 2. Dado el carácter negocial y dispositivo de los acuerdos sociales, no quedan excluidas de la posibilidad anterior ni las pretensiones de nulidad de la Asamblea General, ni la impugnación de acuerdos asamblearios o rectores; pero el árbitro no podrá pronunciarse sobre aquellos extremos que, en su caso, estén fuera del poder de disposición de las partes». La incorporación al texto legal de la referencia al arbitraje cooperativo fue fruto de la aceptación en el Congreso de la enmienda de adición número 201, propuesta por el Grupo Parlamentario Coalición Canaria, dado que no se recogía mención alguna en el Proyecto de Ley de Cooperativas que el Gobierno remitió a las Cortes ${ }^{17}$.

La Disposición Adicional 10. ${ }^{a}$ se estructura en dos apartados, si bien es posible distinguir cuatro reglas perfectamente diferenciables. En primer lugar, "las discrepancias o controversias que pueden plantearse en las cooperativas, entre el Consejo Rector o los apoderados, el

16 Para Trujillo Díez la valoración de esta regulación debe ser negativa, por razón de su oscuridad en la redacción y en su significado. TRujlLLo DíEz, I.J. El arbitraje cooperativo..., cit., pág. 162.

17 Sobre ello puede consultarse, Boletín Oficial de las Cortes General, Congreso de los Diputados, Serie A, número 125-7, de 17 de noviembre de 1998. 
Comité de Recursos y los socios, incluso en el periodo de liquidación, podrán someterse a arbitraje...». Esta regla refleja la conjunción realizada por el legislador estatal entre los criterios tradicionales del arbitraje autonómico y los derivados de las resoluciones de la DGRN y del TS de 1998. El legislador estatal, por un lado, utiliza los criterios tradicionalmente seguidos por las legislaciones cooperativas autonómicas -incluso por él mismo en el rápidamente derogado artículo 163.1 de la Ley de 1987-, al referirse a las discrepancias o controversias que pueden plantearse en las cooperativas, refiriéndose a lo que tradicionalmente se ha expresado como problemas «entre cooperativas, entre éstas y sus socios o asociados, y entre éstos». Pero al mismo tiempo introduce una importante novedad, derivada de la influencia de la resolución de la DGRN de 19 de febrero de 1998, cuando expresamente se refiere a "las discrepancias o controversias que pueden plantearse... entre el Consejo Rector o los apoderados, el Comité de Recursos y los sociosy.

Tradicionalmente las leyes cooperativas se referían únicamente a problemas que surgiesen entre cooperativas, y entre éstas y sus socios, o entre ellos, pero a raíz de la citada resolución de la DGRN, y del reconocimiento expreso que a la misma hace la sentencia del TS de 18 de abril de 1998, el legislador nacional decide incluir, entre los problemas a resolver por la vía del arbitraje cooperativo, los que se planteen entre los cargos orgánicos de las cooperativas aunque no sean socios. La resolución de la DGRN estableció, respecto de los administradores, que «aunque no ostenten la condición de socio, no por ello son terceros del régimen estatutario, en su vinculación orgánica, pues si así fuera tampoco podrían invocar en su favor derechos que, como la retribución, les reconocieran los Estatutos».

En segundo lugar, la Disposición Adicional 10. ${ }^{a}$ realiza una remisión al régimen general del arbitraje, anteriormente regulado por la Ley 36/1988, de 5 de diciembre, de Arbitraje. La Ley 36/1988 ha sido derogada por la Ley 60/2003, de 23 de diciembre, de Arbitraje, por lo que la remisión que realiza la Disposición Adicional 10. ${ }^{a}$ debe ser actualmente entendida en relación al régimen jurídico instaurado por la Ley $60 / 2003^{18}$. Esta regla tampoco es nueva en el mundo del arbitraje cooperativo, y responde a la lógica, pues la remisión a la legislación

18 Sobre la relación entre el cooperativismo y la anterior Ley Arbitral 36/1988, MARTí Miravalls, J. «El arbitraje cooperativo. El caso valenciano», en Revista Jurídica de Economía Social y Cooperativa, 2003, núm. 14, págs. 96 y 97. 
estatal sobre arbitraje aparece en todas las legislaciones autonómicas. Ello supone que actualmente la Ley 60/2003 es la norma de referencia en materia de arbitraje cooperativo, y que, en consecuencia, todas las normas autonómicas que se encarguen de regular el arbitraje cooperativo deberán partir de las bases imperativas que sienta esta norma arbitral estatal.

En tercer lugar, la Disposición Adicional 10. ${ }^{a}$ recoge la preferencia por el arbitraje de derecho frente al de equidad ${ }^{19}$. Este era el aspecto más polémico y difícil de comprender de la Disposición Adicional mientras estuvo vigente la Ley Arbitral 36/1988, en tanto que optaba por una regla contraria a la de la Ley de Arbitraje, que se decantaba por dar prioridad al arbitraje de equidad. Ello podía acarrear algún problema teórico-práctico, sin que se alcanzara a comprender el porqué de esta decisión, dado que las legislaciones cooperativas autonómicas precedentes -País Vasco y Comunidad Valenciana ${ }^{20}$ - expresamente seguían las reglas de la Ley $36 / 1988$, dando prioridad al arbitraje de equidad.

Actualmente esta situación ha cambiado, pues la actual Ley 60/2003, en su artículo 34.1, establece que «los árbitros sólo decidirán en equidad si las partes les han autorizado expresamente para ello». Como se explica en la propia Exposición de Motivos se invierte la regla que la Ley de 1988 contenía a favor del arbitraje de equidad. La preferencia por el arbitraje de derecho en defecto de acuerdo de las partes es la orientación más generalizada en el panorama comparado. Resulta, además, muy discutible que la voluntad de las partes de someterse a arbitraje, sin más especificaciones, pueda presumirse que incluya la de que la controversia sea resuelta en equidad y no sobre la base de los mismos criterios jurídicos que si hubiere de resolver un Tribunal. El arbitraje de equidad queda limitado a los casos en que las partes lo hayan pactado expresamente, ya sea a través de una remisión literal a la «equidad», o a términos similares como decisión «en conciencia», «ex aequo et bono», o que el árbitro actuará como

19 En el arbitraje de derecho los árbitros resuelven con sujeción a derecho, es decir, aplicando el ordenamiento jurídico que corresponda; mientras que en el arbitraje de equidad los árbitros resuelven según su saber y entender, sin tener que justificar su decisión amparándose en el ordenamiento jurídico. Si bien, incluso en el arbitraje de equidad el ordenamiento jurídico es un límite en las decisiones de los árbitros pues no van a poder obviar el derecho imperativo.

20 En tanto que Cataluña opta por una solución mixta. 
«amigable componedor». No obstante, si las partes autorizan la decisión en equidad y al tiempo señalan normas jurídicas aplicables, los árbitros no pueden ignorar esta última indicación.

La incidencia de esta nueva orientación en el caso del arbitraje cooperativo autonómico que se decanta por el arbitraje de equidad es de crucial importancia, en cuanto cambia por completo el sistema instaurado. En principio la cuestión hubiera podido salvarse en tanto que, por una parte, el arbitraje de equidad es lícito en nuestro ordenamiento jurídico; y por otra, si el arbitraje de equidad es lícito, en principio, nada impediría que las instituciones que tengan atribuidas funciones arbitrales opten en su normativa de procedimiento por el arbitraje de equidad. En consecuencia, cuando las partes decidiesen someter sus controversias al arbitraje ante una institución cuya norma de procedimiento se decantase por el arbitraje de equidad habría que considerar que las partes así lo han pactado expresamente como exige la Ley²1. Más complejo jurídicamente, por las razones que se expondrán, parece que hubiera sido la posibilidad de salvar esta polémica por la vía del artículo 1.3 de la Ley 60/2003 — que declara el carácter supletorio de la Ley Arbitral en el caso de los arbitrajes previstos en otras leyes-, y ello por cuanto es al menos discutible que las Comunidades Autónomas puedan dictar, vía fuente legal - esto es, principalmente, Decreto-, normas reguladoras del procedimiento arbitral, en la medida en que el artículo 149.1.6. ${ }^{\circ}$ de la Constitución atribuye al Estado la competencia exclusiva en materia de legislación procesal. No obstante, la Ley 60/2003 de Arbitraje es clara al establecer en su artículo 4.a) que "cuando una disposición de esta Ley... deje a las partes la facultad de decidir libremente sobre un asunto, esa facultad comprenderá la de autorizar a un tercero, incluida una institución arbitral, a que adopte esa decisión, excepto en el caso previsto en el artículo 34». Por consiguiente, habrá que entender que la actual Ley de Arbitraje ha derogado todos los preceptos autonómicos que establecen que, en materia de arbitraje cooperativo, ante el silencio de las partes, prevalece el arbitraje de equidad, puesto que para ello será necesario que las partes expresa y personalmente así lo exijan, sin que sea posible delegar en un tercero, o en una institución arbitral, que adopte esta decisión.

21 Como para el arbitraje de consumo establece la Disposición Adicional 1. a de la Ley 60/2003: "Esta ley será de aplicación supletoria al arbitraje a que se refiere la Ley 26/1984, de 19 de julio, general para la defensa de consumidores y usuarios, que en sus normas de desarrollo podrá establecer la decisión en equidad, salvo que las partes opten expresamente por el arbitraje en derecho». 
Finalmente, el precepto recoge la arbitrabilidad de los acuerdos sociales, salvo en aquellos extremos que estén fuera del poder de disposición de las partes. Este apartado es una copia literal del Fundamento Jurídico Segundo de la sentencia del TS de 18 de abril de 1998. Esta posición mantenida por la LC, y previamente por el TS para el ámbito societario en general, tampoco es una novedad en el mundo cooperativo, ya que la legislación valenciana de cooperativas desde su primera Ley 11/1985, de 25 de octubre, ha recogido expresamente esta posibilidad.

La posibilidad de arbitrar la impugnación de los acuerdos sociales ha sido, desde siempre, la cuestión más problemática en materia de arbitraje societario ${ }^{22}$. En relación con ello, puede considerarse que la legislación cooperativa, a la vista de las actuales posiciones ${ }^{23}$, ha mantenido una posición más avanzada que el resto de legislación sobre Derecho de Sociedades. Desde la primera Ley Valenciana de Cooperativas, Ley $11 / 1985$, de 25 de octubre 24 -artículo 35.2-, hasta la actual Disposición Adicional $10^{\text {a }}$ de la Ley 27/1999, de 16 de julio, y aquellas legislaciones autonómicas que la transcriben —como la riojana-, la legislación cooperativa ha actuado — como así lo ha calificado la doctrina 25 - de "piedra de escándalo en las posiciones contrarias a este arbitraje». Fuera del ámbito cooperativo, la Ley Catalana 7/1997 de Asociaciones, de 18 de junio, también admite en su artículo 15.5 la cláusula estatutaria de sometimiento a arbitraje de las

22 Sobre la impugnación de los acuerdos sociales en las cooperativas, ver SeNENT VIDAL, M.J. La impugnació dels acords social en la cooperativa, Athenea, 2003. Sobre el arbitraje de los acuerdos sociales, PICó I JunoyNÁzquez AlberT, "El arbitraje en la impugnación de acuerdos sociales», Derecho de Sociedades, 1999, págs. 183 y ss; CHULIÁ VICENT, F. «El arbitraje en materia de acuerdos sociales», $R G D, 1998$, pág. 9355; CAMPo VILLEGAS, E. «El arbitraje en las sociedades mercantiles», RJC, 1998, págs. 9 y ss; FERNÁNDEz DEL Pozo, L. "Sobre la arbitrabilidad de las controversias relativas a la impugnación de acuerdos sociales», RGD, 1995, págs. 6913 y ss. Se muestra contrario a la arbitrabilidad de los acuerdos sociales, BOtANA AGRA, M. «Acerca de la sumisión a arbitraje de la impugnación de acuerdos de sociedades anónimas», Derecho de los negocios, 1999, págs. 9 y ss.

23 Principalmente a partir de las importantísimas resoluciones de la DGRN de 19 de febrero de 1998 y del TS de 18 de abril de 1998.

24 Sin duda influenciada por la posición favorable de uno de los «padres» de esta ley, el profesor VICENT CHULIÁ, quien ya había manifestado su posición en algunas de sus obras. Ver, VICENT Chulí, F. «La Asamblea General de la Cooperativa», RJC, 1978, págs. 482 y ss; y Compendio Crítico de Derecho Mercantil, Tirant lo Blanch, 1981, págs. 302 y ss.

25 VICENT CHULIÁ, F. El arbitraje en materia de impugnación..., cit., pág. 365; y «Arbitraje de impugnación de acuerdos sociales. Acto final», Anuario de justicia alternativa, núm. 1, 2001, pág. 107. 
controversias derivadas de los acuerdos adoptados por la Asamblea General de la asociación.

El artículo 2.1 Ley Arbitral 60/2003 establece que «son susceptibles de arbitraje las controversias sobre materia de libre disposición conforme a derecho». En la medida que el arbitraje cooperativo es una modalidad concreta de arbitraje, el objeto del mismo, esto es, las materias que pueden ser sometidas a este tipo de arbitraje, serán todos aquellos conflictos que versen sobre materias de libre disposición y que además revistan interés cooperativo.

Ello permite someter a crítica algunas fórmulas utilizadas dentro del movimiento cooperativo para definir el arbitraje cooperativo. Algunas legislaciones cooperativas autonómicas - como la vasca en su artículo 145.2.f), o la madrileña en el artículo 136.3.e)— definen el arbitraje cooperativo como aquél que ha de resolverse aplicando principalmente normas y principios cooperativos. Esta regla, en principio general, deviene excesivamente restrictiva, por cuanto excluye todos aquellos conflictos que se dan en la práctica cooperativa, con un interés cooperativo directo, pero que se resuelven aplicando normas generales que se excluyen del ámbito específico del derecho cooperativo. Por ello, sería preferible definir el objeto del arbitraje cooperativo no por razón de las normas que pueden aplicarse al conflicto, sino por el interés material cooperativo del mismo, esto es, por el hecho que implique consecuencias materiales para el funcionamiento de la cooperativa, al afectar a la cooperativa o a los socios de la misma como tal.

Ahora bien, no todas las legislaciones autonómicas están en esta línea sino que existen otras que han actuado acertadamente. Por ejemplo, el artículo 3.2 del Reglamento Extremeño de Arbitraje, Conciliación y Mediación Cooperativos dispone un ámbito más amplio en el que incluye tanto los conflictos derivados de la actividad societaria como los provenientes de la actividad cooperativizada, habitualmente no regulada como derecho de cooperativas, cuando establece que sólo podrán ser sometidas a la Comisión de Conflictos Cooperativos aquellas cuestiones litigiosas que versen sobre materias de libre disposición por las partes conforme a Derecho y que se deriven de la actividad cooperativa o asociativa.

En una posición también restrictiva y criticable se encuentran aquellos convenios arbitrales recogidos en los Estatutos de la cooperativa que utilizan, para instaurar el sometimiento de los conflictos a la 
vía arbitral, una redacción general y estandarizada —no sólo en el ámbito cooperativo sino en el societario en general- en virtud de la cual disponen que está sometido a arbitraje la interpretación y aplicación de los Estatutos. Ello ha sido enjuiciado en el ámbito de las sociedades limitadas. Así, en la sentencia de la AP de Orense, de 16 de noviembre de 2002, se rechazó que quedara sometida a arbitraje la impugnación de acuerdos sociales porque no podía entenderse como conflicto relativo a la interpretación y aplicación de los Estatutos. Por ello, sería conveniente la utilización de convenios arbitrales con una redacción más amplia, que diera cabida sin ninguna complicación interpretativa a todos los conflictos que revistan interés cooperativo —-si esta es la voluntad de la Cooperativa-.

Como puede observarse la actual Ley de Cooperativas «dice y hace» más bien poco en favor de la arbitrabilidad de los conflictos cooperativos dado su carácter extremadamente general. Ello puede deberse básicamente — como se ha señalado- a que el legislador estatal entiende que la arbitrabilidad de los problemas cooperativos debe dejarse en manos del propio movimiento cooperativista. Pero sin duda también se debe a que, por un lado, en materia de arbitraje existe en el ordenamiento jurídico un «colchón», como es la legislación arbitral general, que va a marcar la práctica de cualquier tipo de arbitraje, incluido el cooperativo; y, por otro, que existe una importante legislación autonómica a la que sí le preocupa la cuestión y que en gran parte ya la tiene regulada. Si unimos todo ello parece más sencillo comprender las causas por las que el legislador estatal opta por que la Ley 27/1999, de 16 de julio, de Cooperativas, tenga una regulación escasa y general sobre el arbitraje cooperativo, sin que por ello debamos considerarla acertada.

\section{El Cooperativismo y la Legislación Arbitral}

Con la anterior Ley 36/1988, de Arbitraje, se superó el debate propio de la Ley Arbitral de 1953 sobre la aplicabilidad subsidiaria de la normativa arbitral general a los arbitrajes cooperativos. La Disposición Adicional 10. ${ }^{a}$ de la Ley 27/1999, de Cooperativas, no deja lugar a dudas sobre la sumisión del arbitraje cooperativo a la regulación estatal del arbitraje. Basta recordar la derogación de todas las normas autonómicas que establecían la prioridad por el arbitraje de equidad, como consecuencia de la novedad introducida por los artículos 4.a) 
y 34 de la vigente Ley de Arbitraje 60/2003, para observar la primacía de la norma arbitral.

Actualmente, el debate discurre por otros derroteros. Ahora, el arbitraje cooperativo es una materia propia del ámbito autonómico, en tanto que algunas comunidades autónomas que han legislado sobre cooperativas han comprometido su Administración con el mismo. Ello tiene como consecuencia que la polémica se haya centrado básicamente en determinar si el legislador autonómico puede o no atribuir competencias arbitrales y desarrollar el procedimiento a seguir en las instituciones que lo administren, adaptando la normativa general sobre arbitraje a las necesidades propias de la institución administrativa autonómica en la que se impartirá el arbitraje cooperativo.

El artículo 149.1.6. ${ }^{\circ}$ de la Constitución atribuye al Estado la competencia exclusiva en materia de legislación procesal. El Tribunal Constitucional se ha pronunciado en varias ocasiones sobre el arbitraje, como la sentencia 288/1993, de 4 de octubre (RTC 1993/288), donde lo califica de «equivalente jurisdiccional», al conseguir idénticos objetivos que la jurisdicción civil. Por su parte, en la sentencia 15/1989, de 26 de enero (RTC 1989/15), el TC declaró que «el establecimiento de un sistema general arbitral es materia que incuestionablemente ha sido atribuida a la competencia exclusiva del Estado». En consecuencia, la primera conclusión es que las comunidades autónomas no son competentes para dictar normas en materia arbitral.

El problema surge cuando cuatro de las cinco comunidades autónomas que han desarrollado su normativa sobre arbitraje cooperativo - esto es, Comunidad Valenciana, Cataluña, Extremadura y Galicia (únicamente se exceptúa el País Vasco) - han optado por realizarlo a través de Decreto - esto es, a través de un modalidad de fuente legal-, elevando a régimen legal su normativa sobre arbitraje cooperativo, cuando la regulación normativa del arbitraje es exclusiva del Estado. La consecuencia de ello debe ser considerar que actualmente estas comunidades autónomas están invadiendo las competencias del Estado $^{26}$. No obstante, se trata de una cuestión que no ha sido planteada ante el Tribunal Constitucional, por lo que esta legislación está plenamente vigente. Especialmente sangrante es el caso de Cataluña, dado que en su antigua Ley 4/1983, de 9 de marzo, de Cooperativas, no se atribuyeron funciones arbitrales, sino simplemente de con-

26 En el mismo sentido, TRujulo Díez, I.J. El arbitraje cooperativo..., cit., págs. 167 y 168. 
ciliación, precisamente porque en el Dictamen del Consell Consultiu de la Generalitat al Proyecto de Ley se dispuso que «la doctrina del arbitraje cooperativo, tanto si se considera perteneciente al ámbito procesal como a la materia de composición negocial, es competencia exclusiva del Estado...», por lo que no se acierta a comprender por qué en el año 1993 se obvia esta decisión y se opta por desarrollar el arbitraje cooperativo vía Decreto ${ }^{27}$.

Ahora bien, la discusión debe ser entendida en sus justos términos, y tampoco procede un exceso de celo formalista, como en alguna ocasión ha incurrido el propio TC, en lo relativo a las competencias arbitrales atribuidas a las comunidades autónomas. Que la vía del ejercicio de competencias legislativas por parte de las comunidades autónomas para desarrollar su sistema de arbitraje cooperativo no sea el más apropiado desde el punto de vista de coherencia jurídica, no significa que sea contrario al ordenamiento jurídico que éstas atribuyan y desarrollen competencia arbitral alguna en general, y relacionada con el arbitraje cooperativo en particular.

El Tribunal Constitucional en su sentencia 62/1991, de 22 de marzo (RTC 1991/62), declaró inconstitucional un precepto de la Ley Gallega 12/1984, de Consumidores y Usuarios, por invadir la competencia estatal en materia de derecho procesal. En ella se estableció, entre otras cuestiones, que «es evidente que la creación de órganos de naturaleza arbitral y el establecimiento de dicho procedimiento heterocompositivo es materia propia de la legislación procesal civil», y por tanto estatal. Ello constituye un claro ejemplo de exceso de celo por parte del Tribunal Constitucional en la resolución de conflictos de competencias entre Estado y Comunidades autónomas. El artículo 149.1.6. ${ }^{\circ}$ de la Constitución atribuye al Estado la competencia exclusiva en materia de legislación procesal, donde se incluye el arbitraje, pero ello no significa que las Comunidades Autónomas no puedan crear instituciones a las que se les atribuya la capacidad de arbitrar. La propia Ley 60/2003 de Arbitraje, como ya ocurría en la Ley 36/198828, reconoce en su artículo 14.1.a), bajo la rúbrica «arbitraje institucional», que las partes podrán encomendar la administración del arbitraje y la designación de árbitros a... corporaciones de derecho público que puedan desempeñar funciones arbitrales, según sus normas reguladoras.

27 Ver, Dictámenes del Consell Consultiu de la Generalitat de Catalunya, Tomo I, 1981-1982, págs. 300 y 301.

28 Artículo 10. 
No sólo se van a poder atribuir competencias arbitrales a instituciones autonómicas sino que, además, éstas podrán desarrollar el sistema arbitral propio de cada institución para adaptar la norma general a las necesidades concretas del sector, respetando siempre la legislación estatal, tal y como se desprende del apartado segundo del artículo 14 Ley 60/2003, que dispone que «las instituciones arbitrales ejercerán sus funciones conforme a sus propios Reglamentos». Y es que, como ha señalado la doctrina, por muy paradójico que pueda parecer, los Parlamentos autonómicos carecen de competencias para regular el procedimiento arbitral, pero, sin embargo, cualquier corporación de Derecho Público puede administrar arbitrajes y, para ello, dotarse de un régimen reglamentario completo y referido a todos los pormenores del procedimiento arbitral ${ }^{29}$.

De las cinco comunidades autónomas que han desarrollado el procedimiento arbitral cooperativo, cuatro no lo han hecho de una manera especialmente correcta desde el punto de vista de nuestro ordenamiento jurídico, pero la otra, el País Vasco, ha actuado de manera completamente respetuosa con el mismo, regulando el sistema arbitral cooperativo administrado por el Consejo Superior de Cooperativas de Euskadi por medio de un Reglamento interno aprobado a través de resolución adoptada mediante acuerdo plenario por el propio Consejo. Con ello, se consigue dotar al arbitraje cooperativo autonómico de un régimen arbitral propio, respetando la legislación general, sin invadir las competencias estatales expresamente recogidas en la Constitución, y conforme al correcto proceder según la propia Ley 60/2003 de Arbitraje.

Finalmente, respecto a la relación entre cooperativismo y la legislación arbitral estatal, dejar constancia de un hecho significativo que se produjo con la anterior Ley Arbitral 36/1988, y que, o bien revelaba la independencia que para el legislador estatal tenía el movimiento cooperativo, o de lo contrario estábamos ante una situación inexplicable de olvido del mismo. Es lo que la doctrina había calificado como del «silencio cómodo» ${ }^{30}$. Se trataba de la redacción de la Disposición Adicional Primera de la Ley 36/1988, que establecía que dicha Ley Arbitral

29 Trujlllo Díez, I.J. El arbitraje cooperativo..., cit., pág. 164.

30 Merino HeRnández, S. "Administración Pública y sociedades cooperativas: el caso vasco», 1999, pág. 115; y en similar opinión, PANTALEÓN, F. "Análisis crítico del reglamento arbitral del Consejo Superior de Cooperativas de Euskadi», IV Encuentros Cooperativos de la Universidad del País Vasco, 1991, pág. 57. 
sería de aplicación «a los arbitrajes a que se refieren la Ley 26/1984, de 19 de julio, General para la Defensa de Consumidores y Usuarios, el artículo 34.2 de la Ley 33/1984, de 2 de agosto, de Ordenación del Seguro Privado, la Ley 16/1987, de 30 de julio, de Ordenación de los Transportes Terrestres, y el artículo 143 de la Ley 22/1987, de 11 de noviembre, de Propiedad Intelectual, en todo lo no previsto en las mismas y en las disposiciones que las desarrollan... »; pero no disponía nada respecto al arbitraje cooperativo. El porqué de esta situación fue una incógnita, pero la doctrina siempre ha parecido decantarse por la opción de que el legislador guardó un «cómodo silencio» ante la concurrencia de legislación autonómica, máxime cuando un año antes, en la Ley Estatal de Cooperativas de 1987 había recogido un artículo, el 163, relativo al arbitraje cooperativo. Actualmente, la vigente Ley Arbitral 60/2003 únicamente se refiere en su Disposición Adicional Unica al arbitraje de consumo, por lo que el silencio se hace más compresible.

\section{Algunas reflexiones sobre convenio arbitral y conflictos cooperativos}

Con la desaparición de la distinción entre cláusula compromisoria y compromiso, propia de la Ley de Arbitraje de 1953, es posible someter eficazmente a arbitraje, antes de que haya surgido la cuestión litigiosa, todos o parte de los conflictos que puedan originarse en el seno de unas relaciones concretas, en nuestro caso las cooperativas.

El origen del arbitraje se ubica en el convenio arbitral, ya que éste es presupuesto indispensable para que pueda desarrollarse aquél, al ser la autonomía de la voluntad el fundamento sobre el que se asienta y en el que en gran medida centra su eficacia ${ }^{31}$. El convenio arbitral está regulado en los artículos 9 y 11 de la Ley 60/2003. No aparece definido en ninguno de los preceptos, por lo que ha sido la doctrina la que lo ha calificado como el negocio jurídico constitutivo de la obligación de someter a arbitraje la solución de conflictos determinados que hayan surgido o puedan surgir sobre relaciones jurídicas disponibles ${ }^{32}$.

31 Ver, Ortells Ramos, M. Derecho procesal civil, Aranzadi, 2000, pág. 64; y CoRdón MoReno, F. El arbitraje en el Derecho Español: interno e internacional, Aranzadi, 1995, pág. 57.

32 Ortells Ramos, M. Derecho procesal..., cit., pág. 64. 
Partiendo de una doble premisa, que la existencia del convenio arbitral es el presupuesto para que pueda acudirse al arbitraje, y que esta obligación solamente puede nacer cuando exista una voluntad inequívoca de las partes de acudir al mismo, el convenio arbitral puede adoptar la forma de cláusula incorporada a un contrato o de acuerdo independiente, debiendo expresar la voluntad de las partes de someter a arbitraje todas o algunas de las controversias que hayan surgido o puedan surgir respecto de una determinada relación jurídica, contractual o no contractual. Es necesario que éste conste por escrito en un documento firmado por las partes, $u$ otro que deje constancia del acuerdo, siendo válido el convenio arbitral que conste en un documento al que éstas se hayan remitido conforme a la ley. El principal efecto del convenio arbitral es que obliga a las partes a cumplir lo estipulado e impide a los Tribunales conocer de las controversias sometidas a arbitraje, siempre que la parte a quien interese lo invoque mediante declinatoria ${ }^{33}$.

Las vías a través de las cuales puede realizarse un convenio arbitral en materia cooperativa son básicamente dos $^{34}$ : mediante el pacto individual y concreto de los litigantes de someterse al arbitraje de una institución cooperativa, independientemente de si es anterior o posterior al conflicto; y a través de la inclusión de la cláusula arbitral en algún medio de expresión de voluntad de la sociedad cooperativa. El artículo 9.1 de la Ley Arbitral expresamente reconoce que «el convenio arbitral podrá adoptar la forma de cláusula incorporada a un contrato o de acuerdo independiente». La primera no ofrece especiales problemas, mientras que la segunda es más compleja.

La sumisión al arbitraje de una institución cooperativa — pública y autonómica - mediante la inclusión de la cláusula arbitral en algún medio de expresión de voluntad de la sociedad cooperativa se realiza habitualmente a través de su incorporación en los Estatutos Cooperativos. No obstante, también producirá sus efectos la cláusula arbitral si ésta se recoge en cualquier documento interno de la cooperativa que

33 Si bien, éste no impedirá a ninguna de las partes, con anterioridad a las actuaciones arbitrales o durante su tramitación, solicitar de un Tribunal la adopción de medidas cautelares, ni a éste concederlas.

34 Una tercera forma, propia del arbitraje de consumo, es mediante la intervención de la institución arbitral que recoge la solicitud de una de las partes y la traslada a la otra para que si lo desea conteste y acepte el arbitraje (véase Real Decreto 636/1993, de 3 de mayo, de regulación del sistema arbitral de consumo). 
exprese la voluntad de someterse al arbitraje —cuestión distinta será quiénes quedan vinculados por ella-. El convenio arbitral recogido en los Estatutos sociales de la cooperativa puede presentar un problema concreto derivado de la propia esencia del tipo societario cooperativo. El sistema de puertas abiertas propio de las cooperativas podría ser considerado incompatible con la necesidad de que las partes expresen la voluntad de someterse a arbitraje. Podría llegar a interpretarse que la voluntad expresa de someterse al arbitraje recogida en los Estatutos sociales sólo concurre en los socios fundadores de la cooperativa, pero no en los nuevos y en los futuros socios. La cuestión ha sido rotundamente resuelta por la doctrina jurídica y científica. En este sentido, la resolución de la DGRN de 19 de febrero de 1998 declaró que la cláusula arbitral incorporada en los Estatutos sociales tiene plena eficacia tanto frente a los socios fundadores, como a los socios actuales, e incluso frente a los futuros - doctrina que fue seguida por el TS en su sentencia de 18 de abril de 1998 y aplaudida mayoritariamente por la doctrina-.

La doctrina ha apuntado también, con respecto a los nuevos socios, la vinculación automática de éstos, en tanto que, por una parte, su desconocimiento no puede oponerse frente a la eficacia de la publicidad registral ${ }^{35}$; y, por otra, cuando un nuevo socio consiente formar parte de una cooperativa, este consentimiento se hace extensible a todas las cláusulas de los Estatutos rectores de la misma, sin que sea de recibo exigir un consentimiento expreso y específico con respecto a regla rectora alguna —incluida la cláusula arbitral — ${ }^{36}$.

Mayores problemas está dando, a la vista de las últimas sentencias, los efectos de la cláusula arbitral incorporada en los Estatutos de la cooperativa cuando la Ley aplicable al conflicto permite a una de las partes la posibilidad de acudir a la vía arbitral o a la jurisdiccional. Por

35 Por todos, FernándeZ Del Pozo, «Publicidad mercantil registral del procedimiento arbitral», RCDI, núm. 612, 1992, pág. 2043; y MuÑoz PLANAS, «Algunos problemas del arbitraje en materia de sociedades mercantiles», Estudios de Derecho Mercantil en homenaje a RODRIGO URIA, 1978, pág. 418. No obstante, existe una opinión doctrinal contraria -representada por GonzÁlez García, «La llamada cláusula arbitral», Món Jurídic, núm. 121, 1995 - que ha sido mayoritariamente criticada por todos, véase CAMPO VILLEGAS, «El arbitraje en las sociedades mercantiles», RJC, 1998, pág. 324.

36 Como pone de relieve Muñoz Planas, Algunos problemas..., cit., pág. 418, en la doctrina italiana la cuestión se resuelve en sentido favorable a la vinculación en base al principio de que los acuerdos procesales son eficaces también frente a quienes suceden en la posición jurídica del que los estipuló. 
un lado, la Ley de Arbitraje establece que el principal efecto del convenio arbitral es que obliga a las partes a cumplir lo estipulado e impide a los Tribunales conocer de las controversias sometidas a arbitraje, artículo 11.1 de la Ley 60/2003. Por otro lado, las resoluciones de la DGRN y del TS de 1998 declararon que la cláusula arbitral incorporada en los Estatutos sociales tiene plena eficacia tanto frente a los socios fundadores, como a los socios actuales y futuros. Pese a ello, alguna jurisprudencia está provocando un nuevo problema jurídico, en aplicación de una doctrina que peca de exceso de celo jurisdiccional, no admitiendo la excepción de falta de jurisdicción, y declarando la competencia de los Tribunales para conocer de conflictos que en los Estatutos de la cooperativa están sometidos a arbitraje. Son exponentes de esta posición las sentencias de la AP de Valencia de 6 de noviembre de 2000 (RJ 92157/2001) y 10 de julio de 2002 (RJ 244346/2002).

En la sentencia de la AP de Valencia, de 10 de julio de 2002, el objeto del litigio era la expulsión de un socio de la cooperativa. Los Estatutos de la sociedad, en su artículo 42, establecían que «la solución a las cuestiones litigiosas y reclamaciones que puedan surgir entre la Cooperativa y sus socios, se someterán, agotada la vía societaria, al Arbitraje Cooperativo regulado por la Ley en todos los supuestos en los que no esté expresamente prohibido, con el compromiso expreso de esta Cooperativa y de sus socios de cumplir el laudo que en su día se dicte». El problema, creado por el propio Tribunal, se produjo en la interpretación que realizaba del artículo 18.2 de la Ley de Cooperativas de la Comunidad Valenciana 1/1998, de 23 de junio, que disponía que «... el socio expulsado podrá someter este acuerdo de la asamblea al arbitraje cooperativo regulado en ésta ley o impugnarlo en la vía jurisdiccional...».

La posibilidad de optar que confiere la Ley al socio expulsado llevó incompresiblemente al Tribunal a señalar que "sobre la invocada excepción de falta de jurisdicción, ésta se funda en una errónea interpretación de la legislación cooperativa autonómica, en concreto del artículo 18.2 del Decreto Legislativo 1/1998, de 23 de junio, en relación con el artículo 42 de los Estatutos de la Cooperativa demandada, normas que desenvuelven las vías impugnatorias admisibles frente a los acuerdos de expulsión de los socios adoptados por el Consejo Rector y confirmados por la Asamblea General. Ante la alegación manifestada por la apelante se debe señalar que si bien existe una adaptación de los Estatutos de la entidad demandada, recurrente en esta alzada, a lo prevenido por la Ley de Cooperativas de la Comunidad 
Valenciana - Ley 3/1995, de 3 de marzo, tras la publicación del Decreto Legislativo autonómico referido-, debe significarse que dicho texto legal, en su artículo 18.2 dispone expresamente que el socio expulsado "podrá" someter el acuerdo de la Asamblea General que ratifique el acuerdo de expulsión al arbitraje cooperativo o bien impugnarlo ante la jurisdicción ordinaria. Por consiguiente, la elección de acudir a la vía arbitral o a la jurisdiccional constituye un derecho del socio, de manera que las determinaciones estatutarias no pueden contener una norma de carácter imperativo contra lo prevenido en el texto de la ley, según se deduce expresamente de los términos anteriormente expuestos y de la conjunción disyuntiva empleada por el legislador, más aun cuando dicho precepto debe ser interpretado, en todo caso, en relación con el principio de la tutela judicial efectiva consagrado en el artículo 24.1 de la Constitución. En igual sentido se manifiesta el Ministerio Fiscal, en su Informe emitido en fecha 29 de abril de 2002 al señalar que "a tenor del artículo 18.2 del Decreto Legislativo 1/98, de 23 de junio, en relación con el artículo 42 de los Estatutos de la Cooperativa demandada, que al tener la parte actora, el socio demandante, un derecho de elección entre la vía arbitral o jurisdiccional, al haber optado por esta última, en base al Decreto citado, en relación al artículo 24 de la Constitución, no puede prosperar la tesis de la apelante de incompetencia de jurisdicción". En consecuencia, tal alegación procede ser desestimada».

Evidentemente, en tanto así lo establecía el precepto legal, la opción entre elegir someter el conflicto a la vía jurisdiccional o a la vía arbitral era un derecho del socio. El problema está en que el Tribunal parece olvidar que éste ejerce libremente la opción cuando decide ser socio de la cooperativa si ésta prevé dicha cuestión en sus Estatutos, o cualquier otro documento de los válidos para ello - como se desprende de las resoluciones de la DGRN y del TS de 1998-, sin que sea válida la afirmación de que «las determinaciones estatutarias no pueden contener una norma de carácter imperativo contra lo prevenido en el texto de la ley». El convenio arbitral incorporado a los Estatutos sociales constituye una norma de carácter imperativo para los socios que libremente deciden formar parte de la Cooperativa y regirse por sus Estatutos. Pero ello no contradice la norma legal cuando ésta permite al socio, en el reconocimiento de uno de sus derechos, la posibilidad de optar entre varios extremos, en este caso, la sumisión al arbitraje o la jurisdicción. Por consiguiente, el Tribunal debería haber admitido la excepción procesal de falta de jurisdicción. 
El derecho del socio a elegir entre someterse a la vía arbitral o jurisdiccional puede ejercerse en dos momentos distintos, siendo ambos perfectamente lícitos. El primero, previo a la existencia del conflicto -artículo 9.1 Ley 60/2003-, cuando éste decide incorporarse a una cooperativa sometida mediante la existencia de un convenio arbitral en cualquiera de los documentos válidos para ello. En el segundo, que afecta a aquellas cooperativas que no están sujetas a un convenio arbitral, el derecho a optar se ejerce una vez producido el conflicto, esto es, una vez adoptado el acuerdo de expulsión del socio. En este caso, y ante dicho acuerdo, el socio podrá elegir entre acudir a la vía arbitral o a la jurisdicción para resolver su litigio, siendo necesario, en el primer caso, que la cooperativa demandada libremente decida someterse al mismo. Aquí es donde el Tribunal puede admitir la excepción procesal de falta de jurisdicción, dado que no hay ningún documento que obligue al demandado a someterse a la institución del arbitraje, pero ello no era el caso enjuiciado, por lo que no puede compartirse la posición mantenida por la Audiencia.

Todavía puede realizarse un último reproche a la sentencia analizada relativo a la mención al principio de la tutela judicial efectiva. La sentencia, nuevamente de manera desafortunada, establece para justificar su conclusión que "más aun cuando dicho precepto debe ser interpretado, en todo caso, en relación con el principio de la tutela judicial efectiva consagrado en el artículo 24.1 de la Constitución». Olvida el Tribunal la abundante doctrina del Tribunal Constitucional, cuyo máximo exponente es la sentencia 288/1993, de 4 de octubre, en la que califica el arbitraje de «equivalente jurisdiccional» al conseguir idénticos objetivos que la jurisdicción civil. En consecuencia, tampoco parece demasiado oportuno el razonamiento de la sentencia de la AP de Valencia de 10 de julio de 2002 en este extremo, al igual que ocurría con los anteriores.

Más compleja resulta la vinculación de los conflictos que ya se hubiesen originado previamente a la inclusión de la cláusula arbitral en los Estatutos introducida mediante reforma de los mismos. La doctrina es unánime al reconocer que la cláusula arbitral introducida en modificación estatutaria produce plenos efectos. No existe tanta unanimidad respecto al quórum exigido. La mayoría de la doctrina considera que para la introducción con plenos efectos de una cláusula arbitral mediante reforma de Estatutos no será necesario que dicho acuerdo se hubiera adoptado por unanimidad, sino que será suficiente cumplir 
con las mayorías exigidas por la Ley ${ }^{37}$. No obstante, existe alguna voz autorizada que considera que será necesaria la unanimidad para la introducción posterior de la cláusula arbitral en los Estatutos ${ }^{38}$.

La cuestión sobre la posible vinculación a la cláusula arbitral introducida en modificación estatutaria en relación a los conflictos que ya se hubiesen originado previamente a la inclusión de la misma ha sido objeto de algún pronunciamiento doctrinal ${ }^{39}$ y jurisprudencial ${ }^{40}$. Ambos han coincidido a la hora de considerar la no vinculación de dichos conflictos a la cláusula arbitral.

Particularmente reveladora es la Sentencia de la AP de Alicante de 12 de noviembre de 2002 (RJ 53355/2003). En la misma se revoca la sentencia apelada que acogió la excepción arbitral, por cuanto «la reforma de los Estatutos de la Cooperativa demandada a fin de adaptarlos a la nueva normativa reguladora de las Cooperativas en la Comunidad Valenciana, texto refundido de la Ley de Cooperativas aprobado por Decreto Legislativo 1/1998, modificando en concreto los artículos 60 y 13.3 apartado cuarto inciso final de los mismos, fue adoptada por los miembros de la Cooperativa en la Junta de fecha 26 de junio de 1999, pero al final de la misma, según el punto séptimo del orden del día, esto es, una vez que previamente se había ya tomado, como primera cuestión de expresado orden del día, el acuerdo de expulsar de la Cooperativa a los Sres. P. O. y P. G., lo que supone que no habiendo sido aprobada en tal momento la referida reforma estatutaria - en la que se acuerda la inclusión de la cláusula arbitral — la misma, como no existente, no podía desplegar efecto alguno con relación a las posibilidades de impugnación de los acuerdos de expulsión ya consumados, y además ejecutivos desde ese mismo momento, por lo que devenía aplicable tan solo la previsión contenida en el artículo 16.3 penúltimo párrafo de los primitivos Estatutos en cuanto establecía que el socio que sea sancionado con la expulsión podrá impugnar el acuerdo de la Asamblea ante la Jurisdicción Ordinaria». Efectivamente, si el convenio arbitral estatutario no existiese en el momento de producirse el conflicto, sino que se incorpora con posterioridad, éste no podrá afectar a los conflictos ya originados, en tanto que su incor-

37 Por todos, Campo Villegas, E. El arbitraje en..., cit., págs. 332 y ss; Fernández DEL Pozo, L. Publicidad mercantil..., cit., pág. 37.

38 ViCent Chuliá, F. El arbitraje en..., cit., pág. 9357.

39 TRujlllo DíEZ, I.J. El arbitraje cooperativo..., cit., pág. 175.

40 Sentencia de la AP de Alicante de 12 de noviembre de 2002. 
poración no tiene efectos retroactivos, salvo en el caso de que se adoptase la decisión de incorporación por unanimidad y con expresa mención a la concesión retroactiva de la misma.

No sólo en los Estatutos sociales puede recogerse el convenio arbitral sino que también es posible que éstos no recojan mención alguna y que la cláusula de sumisión se incorpore en el Reglamento de régimen interno, o incluso en un simple acuerdo de la Asamblea General, aunque los efectos no serán los mismos.

Si la cláusula se recoge en el Reglamento interno la cuestión está bastante clara en la medida en que obliga de igual manera que los Estatutos, al ser una manifestación más de la capacidad de autorregulación de la cooperativa, y por tanto obliga a todos los socios presentes y futuros.

No ocurre lo mismo si la cláusula se recoge en un acuerdo de la Asamblea, porque, por un lado, al no haber estatutariamente ni reglamentariamente obligación alguna de acudir al arbitraje, puede considerarse que ésta no es la opción normalmente elegida por la cooperativa para resolver sus conflictos; y por otro, pero relacionado con el anterior, cuando la Asamblea decide someter un asunto concreto a arbitraje por acuerdo no lo convierte en un acto de política habitual de la cooperativa, sino que se trata de un simple acuerdo de naturaleza parasocial que vincula de modo accesorio al negocio societario al cual se refiere. En consecuencia, éste sólo tiene eficacia interpartes, de manera que lo único que se podrá decidir por acuerdo de la Asamblea General será el sometimiento singular a un arbitraje concreto entre los ya obligados por ésta.

Analizados los documentos societarios en que podría recogerse el convenio arbitral, queda por investigar las personas a las que vincula el mismo cuando éste está recogido en los Estatutos de la cooperativa - que es el supuesto más habitual- . Sin duda están obligados por el convenio arbitral tanto los socios fundadores como los socios nuevos y futuros, independientemente del tipo de socio de que se trate, excepto si los Estatutos prevén lo contrario. Igualmente queda vinculada la propia Cooperativa, en la medida en que los Estatutos afectan a la sociedad como tal, informando sobre el proceder de la persona jurídica que se crea, siendo ésta — como ha apuntado la doctrina ${ }^{41}$ — la

41 Polo, E. «Introducción y ámbito de eficacia de la cláusula compromisoria en las sociedades mercantiles», en Butlletí TAB núm.4, 1992, pág. 75. 
primera obligada por el convenio arbitral. También están obligados a someterse al arbitraje los Administradores, los miembros del Consejo Rector y de las demás comisiones, así como los interventores, aunque no sean socios, puesto que en la medida en que forman parte de los órganos societarios se verán afectados por la cláusula ${ }^{42}$. Por último, aunque es bastante obvio, no están vinculadas por la cláusula arbitral las controversias entre socios que no traigan causa en el contrato de sociedad cooperativa ${ }^{43}$.

La relación entre arbitraje y sociedades mercantiles es un tema clásico en nuestra doctrina, no obstante ésta se ha centrado básicamente en el ámbito de las sociedades capitalistas. Ahora bien, la cada vez mayor utilización del convenio arbitral en el ámbito cooperativo - que consagra el arbitraje como medio alternativo eficaz de resolución de conflictos cooperativos-, debido principalmente a su incorporación como cláusula de estilo recogida dentro de los modelos de Estatutos ofrecidos por las instituciones públicas, requiere de un particular y detenido estudio sobre este fenómeno, en tanto que - como se ha pretendido demostrar - no se trata de una cuestión ajena a determinados problemas jurídicos, principalmente derivados de la especial naturaleza tanto del arbitraje como de las cooperativas, como, por ejemplo, los distintos efectos que produce el estable-

42 En este sentido se pronunció la RDGRN de 19 de febrero de 1998, que, para el caso de los Administradores, estableció que éstos «están vinculados al régimen estatutario en su relación orgánica con la sociedad, aunque no ostenten la condición de socio». Este es el criterio mayoritariamente seguido por la doctrina, por todos, Fernández del Pozo, op. cit., RDCl, pág. 2044. En contra de este argumento, MuÑoz PlanAS, "Algunos problemas del arbitraje en materia de sociedades mercantiles», Estudios de Derecho Mercantil en homenaje a RODRIGO URÍA, 1978, pág. 421; GonZÁlez GARCíA, "La llamada cláusula arbitral», Món Jurídic, núm. 121, 1995; salvo que éstos sean socios, ya que falta la expresión de la voluntad inequívoca. Para Trujillo Díez, en lo que se refiere a los apoderados la cuestión es más discutible, ya que aunque aparecen mencionados en la Disposición Adicional 10. ${ }^{a}$ LC entiende que éstos deberán aceptar particularmente el arbitraje, pues más allá de la contratación de sus servicios se les considera terceros respecto de la cooperativa y no se encuentran sometidos al contenido de los estatutos, por lo que la mención que se hace en la ley es una invitación a utilizar esta vía en el caso de que así lo estimen oportuno, pero no estarán directamente vinculados por el convenio arbitral. TRUjlLlo Díez, I.J. El arbitraje..., cit., pág. 178.

43 En este sentido se ha pronunciado también la jurisprudencia francesa, véase COHEN, "Arbitrage et société», Bibliothèque de Droit Privé, 1992, pág. 68. Idéntica posición sostiene CARAZO LIÉBANA, "La aplicación del arbitraje a la impugnación de acuerdos societarios en las sociedades de capital», en RDM, 1998, pág. 1220. 
cer el convenio arbitral en un documento $u$ otro de las cooperativas, las personas a las que vincula el mismo o el momento a partir del cual produce sus efectos.

\section{El arbitraje cooperativo en la legislación autonómica}

Como se ha puesto de relieve, el legislador nacional mantiene una posición abstencionista respecto del arbitraje cooperativo institucional. Todo lo contrario ha ocurrido en el ámbito autonómico donde, aunque al menos formalmente, siempre se ha recogido la competencia de la Administración Autonómica para conocer y resolver sobre conflictos cooperativos.

Ahora bien, no todas las comunidades han demostrado el mismo interés por dotarse de una institución pública representativa de su «mundo cooperativo» con capacidad para arbitrar conflictos, e incluso algunas, aún creando esta institución, han optado por no atribuir la competencia arbitral a la misma. En este sentido, se distinguen tres posiciones claramente distintas hacia el arbitraje cooperativo en la legislación cooperativa autonómica -únicamente se analizara la primera por ser la más interesante-. Por un lado están las comunidades autónomas que no sólo han creado una institución pública con competencias arbitrales, sino que además se han encargado de desarrollar reglamentariamente el funcionamiento de dicha institución y competencia. En esta situación se encuentran El País Vasco, La Comunidad Valenciana, Cataluña, Extremadura y Galicia. Por otro lado, una serie de Comunidades Autónomas han creado la institución pública representativa del movimiento cooperativo y le han atribuido la competencia de arbitrar, pero, a diferencia de las anteriores, todavía no han desarrollado su normativa arbitral. En este caso se encuentran Madrid44,

44 En Madrid es el Consejo de Cooperativismo de la Comunidad de Madrid la institución encargada de arbitrar los conflictos cooperativos, en virtud de lo establecido por el artículo 136.3.e) de la Ley 4/1999, de 30 de marzo, de Cooperativas de la Comunidad de Madrid, que dispone que a éste le corresponde «intervenir por vía de arbitraje en las cuestiones litigiosas que se susciten entre las Cooperativas, entre éstas y sus socios, o en el seno de las mismas entre socios, cuando ambas partes lo soliciten o estén obligadas a ello a tenor de sus Estatutos, Reglamento Interno o por cláusula compromisaria. En todo caso, la cuestión litigiosa debe recaer sobre materias que sean de libre disposición por las partes, conforme a Derecho, y afectar primordialmente a la interpretación y aplicación de principios, normas, costumbres y usos de carácter cooperativo». 
Castilla-La Mancha ${ }^{45}$, Navarra ${ }^{46}$ y Andalucía ${ }^{47}$. Finalmente están aquellas Comunidades Autónomas que en sus leyes autonómicas de cooperativas no atribuyen a ninguna institución pública representativa del movimiento cooperativo la competencia de arbitrar, sino que suelen atribuirla a las Uniones, Federaciones y Confederaciones de Cooperativas. Entre ellas se encuentran La Rioja, Aragón, Baleares, y Castilla y León ${ }^{48}$.

45 En Castilla-La Mancha es el Consejo Regional de Economía Social de Castilla-La Mancha el competente para conocer del arbitraje cooperativo, artículo 143.2.d, de la Ley 20/2002, de 14 de noviembre, de Cooperativas, que le atribuye la competencia para "conciliar y ejercer el arbitraje en las cuestiones litigiosas que se planteen entre cooperativas, entre éstas y sus socios, o en el seno de las mismas entre sus socios, cuando ambas partes lo soliciten o bien están obligadas a tenor de lo establecido en sus Estatutos sociales». Por su parte en el artículo 144 se recoge que «1. Los conflictos que surjan entre socios y la cooperativa a la que pertenecen, entre varias cooperativas, entre la cooperativa o cooperativas y la entidad asociativa en que se integren, asi como entre las federaciones de cooperativas, podrán ser sometidos a la mediación, la conciliación o el arbitraje del Consejo Regional de Economía Social de Castilla-La Mancha. 2. El procedimiento para la solicitud y tramitación de los citados mecanismos de resolución extrajudicial de conflictos se desarrollarán reglamentariamente, con arreglo a lo dispuesto en la legislación reguladora del arbitraje de derecho privado». Por ello no es de extrañar que en un futuro cuente con un reglamento arbitral.

46 En Navarra la anterior Ley Foral de Cooperativas 12/1989, de 3 de julio, ya reconocía la capacidad de arbitrar al Consejo Cooperativo de Navarra en su artículo 80.1.b). Actualmente se mantiene en el artículo 81.1.b) de la vigente Ley 12/1996, de 2 de julio, sin que haya ninguna regulación normativa más al respecto.

47 En Andalucía la Ley 2/1999, de 31 de marzo, de Cooperativas de Andalucía, modificada por la Ley 3/2002, de 16 de diciembre —aunque no afecta en nada a la materia del arbitraje cooperativo-, es la encargada de atribuir al Consejo Andaluz de Cooperación, en su artículo 174, la función de arbitrar, el cual deberá respetar las reglas básicas establecidas en el artículo 176, recogiéndose también la obligación de desarrollarlo reglamentariamente.

48 La Rioja en su Ley 4/2001, de 2 de julio, de Cooperativas, únicamente recoge una mención sobre arbitraje y lo hace en su Disposición Adicional Séptima reproduciendo literalmente lo recogido en la Disposición Adicional Décima de la Ley Estatal de Cooperativas, Ley 27/1999, por lo que no crea ninguna institución autonómica a la que se le atribuya la función arbitral. En Castilla y León la Ley 4/2002, de 11 de abril, de Cooperativas tampoco crea ninguna institución administrativa encargada de arbitrar, si bien en su artículo 144.1.g) recoge que corresponde a las Uniones, Federaciones y a la Confederación de Cooperativas el ejercer la conciliación y arbitraje en los conflictos surgidos entre las sociedades cooperativas que asocien o entre éstas y sus socios. La Ley Aragonesa de Cooperativas, Ley 9/1998, de 22 de diciembre, no hace ninguna mención relativa ni a una institución pública ni al arbitraje cooperativo, y únicamente en su artículo 93.6 recoge como competencia de las uniones, federaciones y confederaciones ejercer la conciliación en los conflictos surgidos entre sus entidades asociadas o entre éstas y sus socios; y ejercer cualquier otra actividad de naturaleza análoga. Cabe plantearse si esta última posibili- 
Mención especial merece Castilla y León por cuanto en la conclusión y/o recomendación segunda del Informe Previo sobre el Proyecto de Decreto por el que se regula la Organización y Funcionamiento del Consejo Superior Regional para el Fomento del Cooperativismo, aprobado por la Comisión Permanente del propio Consejo, 27 mayo de 2004, se estableció que "con todas las cautelas que sean necesarias, como su carácter voluntario, etcétera, podía estudiarse la posibilidad de atribuir a este Consejo algún tipo de función de mediación previa a la vía jurisdicional para los conflictos que surjan entre las entidades cooperativas, o entre estas y sus socios, e incluso de actuar con un arbitraje de equidad, más amplio -existe precedente en la Comunidad Valenciana-, de forma más amplia que la reconocida en el artículo 144 letra g) de la Ley a las propias uniones, federaciones y confederaciones». Ello sin duda beneficiaría al movimiento cooperativo castellano-leonés al que se dotaría de una institución — no ajena al fenómeno del cooperativismo- con capacidad suficiente para resolver y evolucionar en lo que a los conflictos cooperativos se refiere. Ahora bien, en fecha de 23 de septiembre de 2004 se aprueba el Decreto 104/2004 —que regula la organización y el funcionamiento del Consejo Superior Regional para el Fomento del Cooperativismo de Castilla y León-, e, incomprensiblemente, en el artículo segundo que establece las funciones del Consejo, no se recoge la de arbitraje. No obstante hay que dejar una puerta abierta en el sentido de que si en un futuro se pretendiese dotar al Consejo de la función arbitral, tal posibilidad sería perfectamente viable a la vista del artículo 2.1.k) del Decreto que estable que el Consejo tendrá «...cuantas otras funciones y competencias se le atribuyan por disposiciones legales y reglamentarias», por lo que no sería de extrañar que, dado que tienen constancia de la posibilidad de realizar tal actividad, se apruebe una norma que atribuya y regule el arbitraje cooperativo ante el Consejo Superior Regional para el Fomento del Cooperativismo de Castilla y León.

dad permitiría atribuir la competencia arbitral o no. Parece que deba responderse negativamente, ya que el legislador autonómico era plenamente consciente de la posición que se mantenía en algunas de las legislaciones autonómicas sobre ello, por lo que su omisión en la norma debió deberse a un acto voluntario, y no un enorme olvido. Finalmente en Baleares, la Ley 1/2003, de 20 de marzo, adopta una posición similar a la de la ley aragonesa, y únicamente recoge en su artículo 151 la competencia de las uniones, federaciones y confederaciones de ejercer la conciliación, pero no dice nada sobre el arbitraje, por lo que me remito a lo anteriormente dicho. 


\section{VI.1. País Vasco}

Otorgada competencia exclusiva a la Comunidad Autónoma del País Vasco en materia de Cooperativas por el artículo 10.23 del Estatuto de Autonomía -y en tanto que uno de los fines del Gobierno Vasco era la promoción y protección de las cooperativas y la singularidad e importancia del movimiento cooperativo en Euskadi- se procedió a dictar la Ley Vasca 1/1982, de 11 de febrero, de Cooperativas. En el Capítulo II del Título II de la Ley 1/1982, referido a las Cooperativas y la Administración, se asumió como función de interés social por parte de los poderes públicos la promoción, estímulo y desarrollo de la cooperación, regulándose el denominado Consejo Superior de Cooperativas, cuyo precedente -establecía la Exposición de Motivos de la Ley 1/1982 - se encuentra en la Ley de Cooperación de 1934 de la Generalitat de Catalunya. Este Consejo, integrado por representantes de las Cooperativas y del Gobierno Vasco, se constituyó como máximo órgano de promoción y representación de las Cooperativas gozando de personalidad jurídica y plena capacidad de obrar, atribuyéndole competencias tan importantes como las de arbitraje, difusión de los principios del cooperativismo y la defensa de los intereses legítimos de la Cooperación -artículo 70-.

En 1988 el Consejo Superior de Cooperativas de Euskadi redactó un Anteproyecto de Ley de Arbitraje Cooperativo que finalmente no alcanzó dicho rango normativo, sino que la competencia arbitral fue desarrollada por el acuerdo plenario del Consejo Superior de Cooperativas de Euskadi, de 9 de febrero de 1989, mediante la aprobación de un Reglamento Interno de Arbitraje ${ }^{49}$ — no utilizándose la vía de la norma legal o Decreto ${ }^{50}$ - Actualmente este reglamento se encuen-

49 Pantaleón calificó de «afortunada» la elección de la forma reglamentaria para regular el arbitraje cooperativo vasco porque, en primer lugar, se cambió de opción en lo relativo al rango normativo que debía tener esta norma, ya que en un principio se pretendía que adoptase forma de ley; y en segundo lugar, y consecuencia de este cambio, porque ello permitió al cooperativismo vasco desarrollar la normativa sobre arbitraje cooperativo sin invadir las competencias estatales en materia civil y procesal. PANTALEÓN, F. «Análisis crítico del reglamento arbitral del Consejo Superior de Cooperativas de Euskadi», IV Encuentros Cooperativos de la Universidad del País Vasco, 1991. En ello influyeron, entre otras cuestiones, las aportaciones del profesor Suso VIDAL. Ver, SUSO VIDAL, J.M. "Análisis del anteproyecto de Ley Vasca de Arbitraje Cooperativo», en I Congreso de Derecho Vasco de Arbitraje, Instituto Vasco de Derecho Procesal, 1988, págs. 148 y 149.

50 Como han hecho las otras autonomías que han desarrollado el arbitraje cooperativo: Comunidad Valenciana, Cataluña, Extremadura y Galicia. 
tra derogado, si bien marcó un punto de inflexión en la evolución del arbitraje cooperativo vasco, por lo que merece ser medianamente explicado.

El Reglamento establecía que al arbitraje del Consejo Superior de Cooperativas podrían someterse todos aquellos asuntos en que concurriesen los siguientes requisitos: que la cuestión litigiosa se plantease entre dos o más Entidades Cooperativas, entre éstas y sus socios, o en el seno de las mismas entre socios a ellas pertenecientes; que en los Estatutos o en el Reglamento Interno de las referidas Entidades Cooperativas se hubiera establecido con carácter obligatorio el sometimiento de tales cuestiones al arbitraje del Consejo Superior de Cooperativas o, en su defecto, que dicho sometimiento se estableciese en la solicitud de arbitraje que formulasen las partes afectadas, o que existiese un convenio arbitral entre las partes; que la cuestión litigiosa se correspondiese principalmente a la interpretación y aplicación de principios, normas, costumbres y usos de naturaleza cooperativa; y que la cuestión litigiosa recayera en materias de libre disposición de las partes conforme a derecho.

La solicitud de arbitraje debía ser cursada al Consejo Superior de Cooperativas de Euskadi por escrito de las partes, y, a la vista de la solicitud y de lo alegado, el Consejo Superior de Cooperativas, en el primer plenario que celebrase, previo informe del Secretario General Técnico, resolvía aceptar o rechazar el conocimiento del asunto mediante acuerdo razonado, reflejando las causas que motivaban o excluían su intervención. El procedimiento arbitral se ajustaba a los principios de audiencia, contradicción e igualdad entre las partes. Para que el asunto fuese recibido a prueba bastaba que una de las partes así lo hubiere solicitado. El término para practicar la prueba era de doce días, pudiendo el árbitro decidir sobre la realización o no de las pruebas propuestas. Desde la finalización del período de prueba o desde la notificación a las partes de la no apertura del mismo, éstas, en el término de seis días, debían presentar sus conclusiones en las que se indicasen las razones en que fundamentan su pretensión. Transcurrido el plazo de presentación de conclusiones, el árbitro dictaba el laudo en un plazo máximo de veinte días.

En este marco se llega al año 1993 en el que se aprueba una nueva Ley Vasca de Cooperativas, Ley 4/1993, de 24 de junio, derogando la Ley de Cooperativas de 11 de febrero de 1982, pero manteniéndose vigente el Reglamento Interno de Arbitraje. La Ley 4/1993 regulaba 
en el artículo 145 el Consejo Superior de Cooperativas de Euskadi, en cuyo apartado segundo, letra f), se establece que éste tendrá competencia para «intervenir por vía de arbitraje en las cuestiones litigiosas que se susciten entre las cooperativas, entre éstas y sus socios, o en el seno de las mismas entre socios, cuando ambas partes lo soliciten o estén obligadas a ello a tenor de sus Estatutos, Reglamento Interno o por cláusula compromisoria. En todo caso, la cuestión litigiosa debe recaer sobre materias de libre disposición por las partes conforme a derecho y afectar primordialmente a la interpretación y aplicación de principios, normas, costumbres y usos de naturaleza cooperativa». Frente a la parca regulación que realizaba el artículo 70.2.f) de la Ley 1/1982, el artículo 145.2.f) de la nueva Ley realiza una más detallada exposición legal sobre el arbitraje cooperativo, sin duda, influenciado por la regulación del citado Reglamento Interno de Arbitraje. Actualmente esta Ley 4/1993 ha sido modificada por la Ley 1/2000, de 29 de junio, de modificación de la Ley de Cooperativas de Euskadi, si bien esta modificación no ha introducido ningún cambio que afecte a la cuestión del arbitraje cooperativo.

A la vista de la nueva regulación y ante la experiencia acumulada en la aplicación del Reglamento anterior, en 1998 se procedió a derogarlo para dotar al sistema arbitral de mayor agilidad, completar determinados trámites del procedimiento no previstos y regular aspectos tales como la gratuidad del mismo o la posibilidad de la conciliación como alternativa al propio arbitraje - contemplada dentro de las facultades atribuidas al Consejo por el párrafo f) del artículo 145.2 de la Ley 4/1993-. Ello se materializa con la aprobación del Reglamento de Arbitraje Cooperativo del Consejo Superior de Cooperativas de Euskadi, aprobado en sesión plenaria el 16 de marzo de 1998 -actualmente vigente- . Se trata de un Reglamento de vital importancia, en tanto se procede a la creación de una estructura formal denominada Servicio Vasco de Arbitraje Cooperativo que nace con vocación instrumental para cumplir, lo más eficazmente, una de las principales funciones del Consejo Superior de Cooperativas de Euskadi, el arbitraje cooperativo.

El Reglamento tiene por objeto la regulación del arbitraje y conciliación cuya administración corresponde al Consejo Superior de Cooperativas de Euskadi, que la ejercerá a través del Servicio Vasco de Arbitraje Cooperativo, órgano que, a diferencia del Consejo, carece de personalidad jurídica propia y depende jerárquicamente del Consejo Superior, sin perjuicio de las facultades y competencias que reglamentariamente se le atribuyen. 
El Reglamento se encarga de desarrollar la regulación del arbitraje ante el Consejo Superior de Cooperativas de Euskadi fijando el ámbito del mismo, el sometimiento al arbitraje, las modalidades de arbitraje, cuestiones sobre su administración - como la caracterización, sede o estructura del Servicio Vasco de Arbitraje Cooperativo-, el desenvolvimiento arbitral, esto es, sujetos, procedimiento, lugar, idioma, postulación, domicilio y comunicaciones, plazos, gastos, etcétera.

El Servicio Vasco de Arbitraje Cooperativo conoce de las cuestiones litigiosas que se susciten entre las cooperativas, entre éstas y sus socios, o en el seno de las mismas entre socios; si bien el conocimiento de las cuestiones litigiosas que se susciten entre los socios cooperativistas se limitará a las que se deriven de la actividad cooperativa, excluyéndose cualesquiera otras que pudieran constituir relaciones particulares entre los mismos. Junto a ello, el Reglamento exige, para someter la controversia a su arbitraje, que las partes estén obligadas a ello a tenor de los Estatutos Sociales o Reglamento de Régimen Interno de la cooperativa; exista convenio arbitral entre las partes, si cualquiera de ellas se dirige a este organismo y solicita su intervención; y/o cuando, surgidas discrepancias entre las partes, exista acuerdo de todas ellas para someterse al arbitraje del Consejo Superior.

El Reglamento establece que son sujetos del arbitraje: las partes legitimadas en la cuestión controvertida y los árbitros, pudiendo las primeras defenderse o actuar ante los árbitros por sí mismas o por medio de representante que tenga capacidad de obrar a tales efectos - representación que debe instrumentarse mediante poder "apud acta», otorgado ante el Secretario del Servicio Vasco de Arbitraje Cooperativo, o notarial- I I ualmente, se encarga de regular, entre otras cuestiones, el procedimiento arbitral en sentido estricto. A fin de no ser exhaustivo se realizará un único apartado en el que se analice el procedimiento arbitral cooperativo en las distintas comunidades autónomas, por lo que su análisis se abordará a continuación. Unicamente, a modo de resumen, puede señalarse que el Reglamento regula los requisitos de la solicitud de arbitraje, el nombramiento del árbitro, las pruebas, las notificaciones y comunicaciones, el cómputo de los plazos, la subsanación de defectos de forma, la inactividad de las partes, la suspensión y desistimiento del procedimiento, el laudo, los recursos, etcétera. En lo no previsto en el Reglamento se estará a lo dispuesto en la Ley Arbitral Estatal 60/2003, correspondiendo al Consejo Superior de Cooperativas de Euskadi la interpretación de todas las cuestiones dudosas o controvertidas que se susciten respecto 
del propio Reglamento. En relación a ello, el Servicio Vasco de Arbitraje Cooperativo puede plantear al Consejo Superior la resolución de cualquier cuestión sobre la interpretación del mismo, debiendo ser resuelta dicha consulta en un plazo de 10 días; y si éste no resolviere la cuestión en plazo, aquél podrá resolver con efecto particular para el caso de que se trate.

En cuanto al Servicio Vasco de Arbitraje Cooperativo, éste está compuesto, a efectos operativos, por Presidente, Secretario y árbitros. El cargo de Presidente corresponde a un miembro del CSCE, designado por el Pleno, de entre los que sean expertos en derecho, y sus funciones son velar para que el Servicio Vasco de Arbitraje Cooperativo actúe correctamente, impulsando su actividad cuando fuere necesario; efectuar las designaciones de los árbitros y las sustituciones que procedan, de acuerdo con lo establecido por el Reglamento; dirigir los servicios administrativos del Servicio Vasco de Arbitraje Cooperativo; y cualesquiera otras que puedan ser delegadas por el Pleno del Consejo Superior de Cooperativas de Euskadi.

El Secretario es el Secretario General Técnico y sus funciones son ejercer la coordinación técnico-administrativa del Servicio Vasco de Arbitraje Cooperativo; velar por su eficacia y funcionamiento; instruir todos los procedimientos arbitrales desde su entrada hasta la puesta a disposición de los árbitros; servir de comunicación, en su caso, entre el Servicio Vasco de Arbitraje Cooperativo y las partes del procedimiento arbitral; ordenar el archivo y custodiar los depósitos de los diferentes procedimientos arbitrales y de conciliación que se sustancien; elaborar una Memoria que informe sobre los expedientes, tanto de arbitraje como de conciliación, para su presentación al Pleno del Consejo Superior de Cooperativas de Euskadi e incorporación, si así se considera oportuno, en la Memoria del citado Consejo; y aquellas otras que le fueran encomendadas por el propio Consejo Superior, a través del Presidente del Servicio Vasco de Arbitraje Cooperativo.

Por su parte los árbitros son a quienes corresponde la resolución de las cuestiones sometidas a arbitraje mediante la redacción de un laudo. Pueden ser árbitros las personas naturales que se hallen en el momento de su aceptación en pleno ejercicio de su capacidad de obrar, siendo necesario, cuando la cuestión litigiosa haya de decidirse con arreglo a Derecho, que éstos sean abogados en ejercicio. El nombramiento debe recaer en persona imparcial, que goce de independencia personal, familiar y patrimonial, respecto a las partes y a la 
cuestión litigiosa. No pueden ser designados árbitros, entre otros, quienes hubieren incumplido su encargo; quienes se encuentren en relación con las partes o con el objeto del arbitraje; ni quienes ostenten la condición de Jueces, magistrados o Fiscales en activo, o ejerzan funciones públicas retribuidas por arancel. La parte que desee recusar a un árbitro debe hacerlo de forma motivada en el escrito inicial de alegaciones a que se refiere el artículo 36 del Reglamento, o dentro de los siete días siguientes al conocimiento por el recusante de las circunstancias que motiven la recusación. La decisión respecto de la recusación le corresponde al Pleno del Consejo Superior de Cooperativas de Euskadi, o a la Comisión específica designada al efecto, quien deberá resolver, en el plazo de cinco días, siendo esta decisión firme y sin posibilidad de recurso alguno.

El Pleno del Consejo Superior de Cooperativas de Euskadi confecciona una lista de árbitros entre los que incluye a personas de notorio prestigio y competencia en el conocimiento de la materia cooperativa, siendo el Presidente del Servicio Vasco de Arbitraje Cooperativo el que designa el árbitro o árbitros que crea idóneos y cumplan los requisitos legales para cada procedimiento arbitral. No obstante, las partes pueden designar de mutuo acuerdo los árbitros, siempre y cuando cumplan los requisitos establecidos en el Reglamento. El arbitraje se administra bien por un único árbitro o por tres árbitros, en cuyo caso se constituirá el Colegio Arbitral, siendo necesario para su constitución la presencia de todos los árbitros. El Colegio Arbitral tiene un Presidente y un Secretario, designados por el Presidente del Servicio Vasco de Arbitraje Cooperativo, y puede delegar en cualquiera de sus miembros para la realización de cualquier acto de tramitación del procedimiento, pero para adoptar sus acuerdos se exige mayoría de los miembros — decidiendo el voto del Presidente en caso de no alcanzarse la mayoría-.

Finalmente, dejar constancia que la legislación cooperativa vasca todavía ha sufrido otra modificación más en lo relativo al arbitraje cooperativo con la aprobación, mediante resolución de 2 de marzo de 2000, del Reglamento de organización y funcionamiento del Consejo Superior de Cooperativas de Euskadi. En éste se adapta la normativa del funcionamiento del Consejo a las novedades introducidas en la legislación cooperativa en los años precedentes, como ocurre con el caso de la creación del Servicio Vasco de Arbitraje Cooperativo. En lo que a arbitraje se refiere, como no podía ser de otra manera, el Reglamento atribuye al Consejo dicha competencia en el artículo 4.2.c) y lo desarrolla en el artículo 7, donde, bajo la rúbrica «Función de arbi- 
traje», establece que los contenidos operativos de la función de Arbitraje son: "a) intervenir por vía de arbitraje en las cuestiones que se susciten entre las cooperativas, entre éstas y sus socios, o en el seno de las mismas entre socios, en los supuestos y condiciones generales que establecen la ley de cooperativas de Euskadi; b) fomentar la conciliación como fórmula de resolución alternativa de los conflictos en el seno de las cooperativas; c) aprobar y modificar el reglamento de arbitraje correspondiente para su regulación y consecución de la máxima seguridad jurídica; d) aplicar el reglamento de arbitraje cooperativo, mediante el Servicio Vasco de Arbitraje Cooperativo, entidad encargada de administrar los arbitrajes; e) difundir el Servicio Vasco de Arbitraje Cooperativo, su actividad, y el reglamento de arbitraje cooperativo entre las cooperativas y sus socios; f) y utilizar las intervenciones arbitrales para dar a conocer el arbitraje y la conciliación, así como la interpretación del marco normativo cooperativo». Por tanto, como puede observarse, no se produce ninguna novedad significativa en lo que a arbitraje cooperativo se refiere, sino que se limita a plasmar en la norma reguladora del Consejo Superior de Cooperativas de Euskadi lo que ya existía en otras normas sobre esta materia, elevando a rango normativo la obligación de potenciar y fomentar el arbitraje cooperativo.

\section{VI.2. Cataluña}

En Cataluña ha sido tradicional la existencia de una institución pública representativa del cooperativismo. Así, ya en 1978 se creó, mediante el Decreto de 16 de octubre, un Consejo Asesor de la Cooperación, sustituido posteriormente por el Consejo Superior de la Cooperación con la aprobación de la primera Ley Catalana de Cooperativas, Ley 4/1983, de 9 de marzo - aunque el Consejo Asesor de la Cooperación no fue efectivamente suprimido hasta 1984 con la aprobación del Decreto 31/1984, de 31 de enero-. En esta primera legislación catalana no se atribuyeron al Consejo Superior de la Cooperación funciones arbitrales, sino meramente conciliadoras, pudiendo mediar éste en las controversias que se produjesen entre los socios y las cooperativas, o entre éstas y sus federaciones, no siendo vinculantes sus decisiones ${ }^{51}$. La causa de que en la Ley 4/1983, de 9 de marzo,

51 El artículo 99 de la Ley establecía que el Consejo debía manifestarse sobre el objeto de la conciliación en el plazo más breve posible, para de esta manera «los afectados puedan acudir dentro del plazo a la jurisdicción ordinaria en el caso de no estar de acuerdo con el veredicto». 
de Cooperativas, no se atribuyeran funciones arbitrales al Consejo Superior de la Cooperación fue consecuencia del Dictamen que emitió el Consell Consultiu de la Generalitat sobre el Proyecto de Ley, en el que se dispuso que «la doctrina del arbitraje cooperativo, tanto si se considera perteneciente al ámbito procesal como a la materia de composición negocial, es competencia exclusiva del Estado... »52.

No fue hasta 1991, con la aprobación de la Ley de Reforma 13/1991, de 1 de julio, cuando por primera vez en la legislación catalana se atribuye al Consejo Superior de la Cooperación funciones arbitrales. Se modificó el anterior artículo 99 de la Ley, introduciéndose la función arbitral, quedando redactado el precepto como sigue: "Artículo 99. Conciliación y arbitraje ante el Consejo Superior de la Cooperación. 1. Las cuestiones que se plantean entre algún socio y la cooperativa a la cual pertenece o entre ésta y la federación en la cual se agrupa pueden ser planteadas a la conciliación ante el Consejo Superior de la Cooperación, o bien directamente a la jurisdicción ordinaria. El procedimiento de conciliación se determinará reglamentariamente. 2. Las cuestiones a que se refiere el apartado 1 pueden ser sometidas, si lo solicitan las partes, al arbitraje de la persona o las personas que designe el Presidente del Consejo Superior de la Cooperación, de acuerdo con la legislación vigente sobre la materia. El procedimiento de formalización y tramitación de estos arbitrajes se determinará reglamentariamente. 3. La presentación de la solicitud de conciliación o de arbitraje interrumpe la prescripción y suspende el transcurso del plazo para el ejercicio de las acciones reguladas en la presente Ley».

La vigencia de este precepto fue bastante esporádica en tanto que a través del Decreto Legislativo 1/1992, de 10 de febrero, se aprobó el Texto Refundido de la Ley de Cooperativas de Cataluña, en el que se regulaba la competencia arbitral del Consejo Superior de la Cooperación en los artículos 107 y 114.2.d) -actualmente derogados por la Ley 18/2002, de 5 de julio, de Cooperativas Catalanas-. No obstante, el artículo 107 del Decreto Legislativo transcribía el anterior artículo 99, mientras que el 114.2.d) únicamente se limita a recoger entre las funciones del Consejo Superior de la Cooperación la competencia para arbitrar ${ }^{53}$, por lo que no se produjo ninguna novedad.

52 Ver, Dictámenes del Consell Consultiu de la Generalitat de Catalunya, Tomo I, 1981-1982, págs. 300 y 301.

53 La composición y funcionamiento del Consejo Superior de la Cooperación fue desarrollada mediante el Decreto 34/1993, de 9 de febrero. El Consejo Superior de la Coo- 
Ahora bien, a partir de esta Ley y tomando en consideración una serie de cuestiones ${ }^{54}$, se procedió a aprobar un Reglamento que desarrollase el procedimiento de formalización y tramitación de arbitrajes ante el Consejo Superior de la Cooperación, el Decreto 177/1993, de 13 de julio. Este Decreto sigue actualmente en vigor, con la única modificación introducida por la Orden de 14 de diciembre de 2001, en la que se modifica el anexo del Reglamento que regula las tarifas de honorarios de los árbitros.

El actual régimen jurídico del arbitraje cooperativo en Cataluña está constituido por la Ley 18/2002, de 5 de julio, de Cooperativas catalanas, y por el Decreto 177/1993, de 13 de julio. El Título IV de la Ley se dedica al Consejo Superior de la Cooperación. En el Capítulo I, artículos 151 a 156, no hay cambios sustanciales en la estructura y el funcionamiento del mismo, ya que toma como base el Reglamento que lo desarrollaba. Concretamente, en el artículo 153.c) se atribuye la competencia para cumplir las funciones de conciliación y arbitraje en los términos que establece la Ley. Por su parte, en el Capítulo II, artículo 157, se regulan las bases de los procedimientos de conciliación y el arbitraje ante al Consejo Superior de la Cooperación. El precepto establece que " 1 . Las cuestiones que son objeto de la presente Ley y las normas cooperativas que la desarrollan que se planteen entre cooperativas, entre algún socio o socia y la cooperativa a la que pertenece, entre socios de alguna cooperativa o entre una cooperativa y la federación en la que se agrupa pueden ser planteadas a conciliación ante el Consejo Superior de la Cooperación, o bien directamente ante la jurisdicción ordinaria, de acuerdo con el Artículo 158. El procedimiento de conciliación se establece por reglamento. 2. Las cuestiones a que se refiere el apartado 1 pueden ser sometidas, si lo solicitan las partes o lo disponen los estatutos sociales, al arbitraje de la persona o personas que designe el presidente o presidenta del Consejo Superior

peración se presenta como un organismo colaborador de la Generalitat de Catalunya en todo el ámbito de competencias que sobre cooperativas le corresponden, constituyéndose como un órgano consultivo, de participación y mediación de la Administración de la Generalitat, y desarrollará sus funciones con autonomía funcional en el marco de competencias que tiene atribuidas.

54 Como la naturaleza jurídica del Consejo Superior de la Cooperación como órgano consultivo, de participación y mediación de la Administración de la Generalitat; los artículos 107.2 y 114.2.d) del Decreto Legislativo 1/1992, de 10 de febrero; y el artículo 61 de la Ley 13/1989, de 14 de diciembre, de organización, procedimiento y régimen jurídico de la Administración de la Generalitat de Catalunya, de conformidad con el dictamen preceptivo emitido por la Comisión Jurídica Asesora. 
de la Cooperación, de acuerdo con la legislación vigente. El procedimiento de formalización y tramitación de estos arbitrajes se establece por reglamento. La competencia en materia de arbitraje del Consejo Superior de la Cooperación no excluye la facultad de las partes de someter sus diferencias a otras formas de arbitraje, de acuerdo con lo que dispone la legislación aplicable. 3. La presentación de la solicitud de conciliación o arbitraje interrumpe la prescripción y suspende la cuenta del plazo para el ejercicio de las acciones reguladas por la presente Ley». Esto no es sino la plasmación legal de las reglas que establecía el Decreto 177/1993, de 13 de julio, sobre arbitraje, y 118/1993, de 6 de abril, sobre conciliación.

Para finalizar señalar que el Reglamento de Arbitraje del Consejo Superior de la Cooperación regula, en sus 22 artículos, todas las cuestiones relativas al arbitraje cooperativo. En este sentido, el Reglamento se pronuncia sobre los conflictos susceptibles de arbitraje, la cláusula de sumisión, algunas disposiciones generales, la representación y defensa de las partes, los requisitos de la demanda de solicitud de arbitraje, la admisión de la demanda a trámite y la aceptación del arbitraje, la oposición al mismo, el nombramiento de los árbitros, la aceptación del cargo, la recusación, la comparecencia inicial, la posibilidad de una solución extra-arbitral, la estructura y desarrollo del procedimiento, el laudo arbitral, su eficacia y protocolización, los errores materiales en el laudo arbitral, su incumplimiento, los plazos y, finalmente, los honorarios de los árbitros y los gastos de tramitación. Únicamente destacar que, según el Reglamento, pueden ser sometidos al arbitraje del Consejo Superior de la Cooperación los conflictos que se originen entre algún socio o adherido 55 y la cooperativa a la que pertenece, entre una cooperativa y la federación donde se encuentra afiliada, entre cooperativas y entre federaciones de cooperativas, o entre éstas y la Confederación de Cooperativas de Cataluña. La sumisión en el arbitraje del Consejo Superior de la Cooperación se produce bien por cláusula compromisoria, establecida estatutaria o reglamentariamente, o bien por acuerdo entre las partes para someterse expresamente. En cualquier caso, tanto el convenio arbitral como la cláusula de sumisión se deberán formalizar por escrito.

55 Téngase presente que en la Ley 18/2002 se sustituye la figura del adherido por la del socio colaborador, tal y como se recoge en la Exposición de Motivos. 


\section{VI.3. Comunidad Valenciana}

El arbitraje cooperativo en la Comunidad Valenciana, por un lado, siempre ha estado presente en la legislación cooperativa valenciana; y, por otro, al igual que tradicionalmente había ocurrido en el arbitraje cooperativo estatal, ha sido desde siempre un arbitraje institucional. Por ello se hace conveniente realizar un breve repaso de las instituciones valencianas que se han encargado del fomento del cooperativismo valenciano y a las que en su momento se les atribuyó la función arbitral $^{56}$.

En primer lugar, en 1979 se dotó al Consell del País Valencià, mediante Decreto de 24 de enero, de un Consejo Asesor de la Cooperación, con una composición y unas competencias acordes con el Consell de aquel momento, por lo que lógicamente no recogía la función arbitral. Una vez promulgado el Estatuto de Autonomía de la Comunidad Valenciana y con la atribución a la comunidad de competencias exclusivas en materia de cooperativas se hizo necesario aprobar una nueva norma reguladora del hasta entonces Consejo Asesor de la Cooperación que se adaptase a la nueva realidad, y mediante el Decreto 26/1984, de 21 de marzo, se creó el Consejo Asesor de Cooperativas, que sustituía el antiguo Consejo Asesor de la Cooperación, constituyéndose como un órgano de asesoramiento, participación y promoción del movimiento cooperativo valenciano, si bien entre sus funciones aún no se recogía la competencia arbitral.

Con la primera Ley de Cooperativas de la Comunidad Valenciana, Ley 11/1985, de 25 de octubre, aparece el Consejo Superior del Cooperativismo, creado como órgano colaborador de la Generalitat Valenciana en las competencias que la misma tiene encomendadas en materia de cooperativismo, con personalidad jurídica propia y plena capacidad para realizar los actos necesarios para el cumplimiento de sus funciones. Fue a este Consejo Superior del Cooperativismo al que en el artículo 108 de la Ley se le atribuyó, por vez primera en la legislación valenciana, funciones arbitrales y de conciliación. No obstante, el Consejo Asesor de Cooperativas siguió existiendo hasta que, mediante el Decreto 170/1986, de 29 de diciembre, regulador del Consejo Superior del Cooperativismo, se derogó el Decreto 26/1984 y se suprimió el Consejo Asesor de Cooperativas, integrándose sus funcio-

56 Martí Miravalls, J. «El arbitraje cooperativo. El caso valenciano», en Revista Jurídica de Economía Social y Cooperativa, 2003, núm. 14, pág. 83. 
nes en el nuevo Consejo Superior del Cooperativismo. Este Decreto 170/1986 no sólo es importante porque acaba con el Consejo Asesor de Cooperativas, sino también porque en su misión de desarrollar las competencias del nuevo Consejo dedicaba el Capitulo II, artículos 6 a 10, a regular el arbitraje y la conciliación cooperativa ${ }^{57}$.

Fruto de esta regulación en el año 1994 se empiezan a tramitar por primera vez conciliaciones ante una institución cooperativa de la Administración Pública Valenciana, el Consejo Superior del Cooperativismo ${ }^{58}$. Ese año no sólo se practicaron conciliaciones sino que también se realizó el primer arbitraje cooperativo valenciano. En fecha de 16 de diciembre de 1994 se presentó la demanda de arbitraje y el día 13 de julio de 1995 se dictó el primer laudo del movimiento cooperativo valenciano.

El problema fue que por falta de presupuesto la actividad arbitral se paralizará totalmente — pese a que con la aprobación de la Ley 3/1995, de 2 de marzo, que modificó la Ley 11/1985, sustituyendo el Consejo Superior del Cooperativismo por el actual Consejo Valenciano

57 El precepto establecía que para la resolución de los conflictos que se plantasen entre Entidades Cooperativas o entre éstas y sus socios, se podría instar ante el Consejo Superior del Cooperativismo la celebración de conciliación previa al ejercicio de acciones ante los Tribunales, o la realización de un arbitraje de derecho o de equidad. La reclamación previa de conciliación o la demanda de arbitraje, interrumpía la prescripción y suspendía la caducidad de las acciones, de acuerdo con la legislación estatal. El procedimiento y recursos en el supuesto de arbitraje, sea de derecho o de equidad, eran los previstos en la Ley Arbitral de 1953; y para que el Consejo Superior de Cooperativismo pudiese emitir laudos arbitrales, era preciso que las partes en conflicto se hubiesen obligado previamente, bien de forma voluntaria, bien por sentencia judicial en cumplimiento de una anterior cláusula compromisoria inserta en los Estatutos Sociales de las Entidades Cooperativas o fuera de éstos. Si el compromiso era de arbitraje de derecho, el laudo sería emitido y firmado por uno o tres Licenciados en Derecho miembros del Consejo o miembros de la Corte de Arbitraje Cooperativo que el Consejo estaba facultado para nombrar entre Licenciados en Derecho expertos en Cooperativas. Si el compromiso era de arbitraje de equidad o de amigable composición podían emitir y firmar el laudo, en nombre del Consejo, miembros de éste que no fuesen Juristas.

58 La primera demanda de conciliación que se tramitó fue la correspondiente al expediente 1/1994, en la que, tras la presentación de la solicitud en fecha de 21 de noviembre de 1994, se celebró el primer acto de conciliación el día 12 de diciembre de 1994, dándose el acto sin efecto por incomparecencia de la demandada. El segundo expediente, el 1/1995, conoció de la solicitud de conciliación más antigua, de fecha de 25 de febrero de 1994, realizándose el acto de conciliación en fecha de 23 de enero de 1995, con idéntico resultado que el anterior. Y el primer acto celebrado con presencia de las dos partes fue el correspondiente al expediente 2/1995, celebrado el 23 de mayo de 1995, aunque no hubo avenencia. 
del Cooperativismo, propugnaba el fomento del mismo- hasta el punto que esta actividad no se reanudará hasta el año 1999, para las conciliaciones, y 2001 para arbitrajes ${ }^{59}$.

La sustitución del Consejo Superior del Cooperativismo y la creación del Consejo Valenciano hizo necesaria una nueva regulación que reemplazara el Decreto 170/1986 y regulase el actual Consejo Valenciano del Cooperativismo. Ello se produce con la aprobación del todavía vigente Decreto 228/1996, de 10 de diciembre, regulador del Consejo Valenciano del Cooperativismo. La sustitución del Consejo Valenciano del Cooperativismo por el antiguo Consejo Superior de Cooperativismo no fue sólo un cambio nominal sino también de naturaleza, ya que el nuevo Consejo no tendrá atribuida, a diferencia del anterior, personalidad jurídica, por lo que era necesario realizar una nueva reglamentación que reemplazase al Decreto 170/1986.

El Decreto 228/1996, respecto del procedimiento de conciliación, estableció, como novedad, el carácter facultativo de la comparecencia de las partes ante la Comisión de Conciliación, teniendo en cuenta, entre otros motivos, las eventuales dificultades que para su presencia personal puedan concurrir en los interesados ${ }^{60}$; mientras que en cuanto a la regulación del procedimiento de arbitraje no introdujo un especial desarrollo, bajo la justificación de la remisión que en la Ley de Cooperativas de la Comunidad Valenciana realizaba a la normativa estatal en lo que se refiere a procedimiento y recursos.

El Decreto 228/1996 establecía que el Consejo Valenciano del Cooperativismo debía dotarse de un Reglamento que regulase su funcionamiento y, en cumplimiento de esta previsión, el Pleno del Consejo aprobó, en fecha de 26 de enero de 1999, el Reglamento de funcionamiento, en cuyo Capítulo III, artículos 19 a 35, se regula la conci-

59 Paradójicamente durante este periodo se siguieron solicitando conciliaciones y arbitrajes, si bien los medios no eran los más oportunos y únicamente se contestaba a las solicitudes comunicándoseles que no era posible su tramitación en esa fecha -y no en todos los casos-.

60 La conciliación correrá a cargo de una Comisión Delegada del Consejo Valenciano del Cooperativismo, la cual emitirá una recomendación que, de ser aceptada por las partes, tendrá los mismos efectos que un laudo arbitral, incluida la ejecutoriedad. Ello también se reconocía en el anterior Decreto 170/1986, artículo 10.3.3, y en los artículos que regulaban la conciliación en las LCCV — la actual Ley 8/2003 también lo hace, artículo 123.1.a- Actualmente la normativa catalana sobre conciliación, Decreto 118/1993, de 6 de abril, artículo 7.6, tiene una regulación muy similar. 
liación y el arbitraje. Esta norma realiza una minuciosa regulación de los distintos procedimientos, si bien ha sido modificada mediante acuerdo del Pleno del Consejo de fecha de 5 de mayo de 2000, el cual ha introducido importantes cambios en materia arbitral.

Actualmente, tras la Ley Valenciana de Cooperativas 8/2003, de 24 de marzo, las funciones del Consejo Valenciano del Cooperativismo, atendiendo al artículo 122 de la Ley, son informar, dictaminar o formular proposiciones sobre cualquier disposición legal que pueda afectar a las entidades cooperativas; fomentar y potenciar el movimiento cooperativo y las relaciones intercooperativas; participar en la difusión de los principios cooperativos y velar por su cumplimiento, en particular por la utilización del fondo de educación y promoción cooperativa; fomentar la educación y formación cooperativa; colaborar en la ejecución de la política del gobierno valenciano en relación con el cooperativismo; intervenir en los conflictos que se planteen en materia cooperativa, por vía de conciliación o arbitraje, en la forma regulada en la Ley de Cooperativas y en el Decreto; emitir el previo informe a que se refiere el artículo 106 de la Ley de Cooperativas de la Comunidad Valenciana a la decisión de intervención temporal de cooperativas; acordar el destino del haber líquido resultante en los procesos de liquidación, en el supuesto a que se refiere el artículo 66 bis. 6 de la Ley Valenciana; y las demás funciones que le atribuya tanto la Ley de Cooperativas como el resto de la normativa.

El Consejo Valenciano del Cooperativismo está compuesto por miembros natos, que son el Conseller competente y el titular del centro directivo de dicha Consellería; y por ocho miembros electivos, tres a propuesta del Conseller de entre personas con experiencia reconocida en el sector del cooperativismo y de la economía social en general, y cinco a propuesta de la Confederación de Cooperativas de la Comunidad Valenciana ${ }^{61}$. Estos son nombrados por el Gobierno Valenciano mediante Decreto ${ }^{62}$. Con el fin de que los distintos ámbitos de la administración de la Generalitat Valenciana puedan conocer más inmediatamente la realidad del sector cooperativo, el Consejo Valenciano

61 Se hecha en falta la representación de algunos sectores concretos como el universitario el cual si que se recoge en algunas leyes autonómicas de cooperativas como la de Euskadi, artículo 145.3, Madrid, artículo 136.4, o Galicia, artículo 136.1.

62 La propuesta de nombramiento de los miembros electivos incluye la de un número equivalente de suplentes para el caso de ausencia, vacante o enfermedad de aquéllos, con un orden de preferencia entre los mismos. 
del Cooperativismo podrá solicitar la presencia, cuando se trate de cuestiones relacionadas con la materia de su departamento respectivo, de los vocales de la Comisión Interdepartamental de Cooperativas de la Comunidad Valenciana ${ }^{63}$, quienes en ningún caso tienen derecho de voto en las reuniones del Consejo Valenciano del Cooperativismo.

Como recoge el artículo 123 de la actual LCCV, en la resolución de conflictos que se planteen entre entidades cooperativas o entre éstas y sus socios o miembros, el Consejo Valenciano del Cooperativismo ejerce una doble competencia: la conciliación previa, de carácter voluntario al ejercicio de acciones ante los tribunales; y el arbitraje de derecho o de equidad. Para ejercer dicha tarea será preciso que las partes en conflicto se hayan obligado previamente mediante convenio arbitral, en virtud de la cláusula inserta en los estatutos sociales de las cooperativas o fuera de éstos, el cual deberá expresar también que la administración del arbitraje y la designación de los árbitros se realizarán por el Consejo Valenciano del Cooperativismo, así como que aceptan el sometimiento a la resolución arbitral en sustitución de la jurisdiccional.

A tales efectos se crea la Comisión de Arbitraje y Conciliación, formada por cinco miembros, elegidos por el Pleno de entre sus miembros $^{64}$, eligiéndose al Presidente y Secretario, y quedando válidamente constituida con la presencia de todos sus miembros ${ }^{65}$. De no lograrse ese quórum en primera convocatoria, queda válidamente constituida en segunda convocatoria una hora más tarde con la presencia de tres miembros, actuando, en su caso, de Presidente y Secretario el miembro de mayor edad y el más joven, respectivamente. Los acuerdos se adoptan por mayoría de votos de los presentes, y las convocatorias se efectúan por el Presidente, a iniciativa propia o a propuesta de dos miembros de la comisión, debiendo contener el Orden del Día. En el segundo caso, si transcurren diez días desde la propuesta de convo-

63 La Comisión Interdepartamental de Cooperativas de la Comunidad Valenciana, creada y regulada por el Decreto 99/1996, de 21 de mayo, es el órgano encargado de coordinar las acciones del Gobierno Valenciano en materia de cooperativas, cohesionando y dando una visión de conjunto y unidad a los programas de actuación de la Generalitat relativos a las cooperativas.

64 Tres de ellos a propuesta de la Administración, ejerciendo siempre uno de estos el cargo de Secretario de la Comisión, artículo 19 del Reglamento de funcionamiento del Consejo de 26 de enero de 1999 —introducido por la modificación de 5 de mayo de 2000-

65 Artículo 21 del Reglamento. Novedad introducida por la modificación del 2000, ya que anteriormente bastaba con la presencia del Presidente, el Secretario y un miembro. 
catoria de los dos miembros sin que el Presidente la haya convocado, éstos quedan facultados para convocarla por sí mismos con el mismo Orden del Día que habían propuesto. Únicamente podrá someterse a votación o deliberación un asunto que no forme parte del Orden del Día siempre que estén presentes todos los miembros de la misma y acuerden su tratamiento por mayoría.

Por otro lado, las partes son perfectamente libres de acordar el tipo de arbitraje por el que se va a regir el proceso, derecho o equidad, fijando peculiaridades concretas para cada clase. En el arbitraje de derecho los árbitros, en la resolución del conflicto, habrán de actuar dentro del marco normativo vigente. Por ello, para este tipo de arbitraje los árbitros, ya sea uno —es lo más habitual — o tres, necesariamente deberán ser licenciados en Derecho, independientemente de si son miembros del propio Consejo o bien expertos en cooperativas - ajenos al Consejo- nombrados por éste para que formen parte de la Corte de Arbitraje Cooperativo ${ }^{66}$ —es lo más habitual-, en virtud de la autorización legal contenida en el artículo 123.1.b.2 LCCV y en el artículo 12 del Decreto 228/1996. Por su parte, para el arbitraje de equidad, los árbitros habrán de decidir la cuestión según su saber y entender, por lo que podrán resolver miembros del Consejo o terceros designados por el Consejo — que también suelen ser licenciados en Derecho expertos en cooperativas-.

Finalmente, en cuanto al procedimiento arbitral en sí, señalar que éste se encuentra regulado en los artículos 26 a 35 del Reglamento de funcionamiento del Consejo Valenciano del Cooperativismo, de 26 de enero de 1999, modificado por acuerdo del Pleno del Consejo de 5 de mayo del 2000.

\section{VI.4. Extremadura}

En el ejercicio de la potestad legislativa sobre las sociedades cooperativas que la Comunidad Autónoma de Extremadura tiene atribui-

66 No parece demasiado acertado el hecho de que los árbitros puedan ser miembros del Consejo por cuanto algunos de éstos, normalmente los designados, son abogados a sueldo de Cooperativas, por lo que se está dotando de la capacidad para ser árbitro a personas que, o bien tienen una estrecha relación con una de las partes (las Cooperativas) o que incluso dependen económicamente de ellas. Por ello hubiese sido preferible que se atribuyese dicha calidad a terceros totalmente independientes de las partes como pueden ser los profesores universitarios. 
da en virtud del artículo 62.2 del Estatuto de Autonomía de Extremadura - que faculta a la Junta de Extremadura a realizar acciones de fomento de este tipo de sociedades-, se procedió a aprobar, en fecha de 26 de marzo de 1998, la Ley 2/1998 de Sociedades Cooperativas de Extremadura. Esta norma respondía a dos principios generales: uno, dar libertad de regulación a las sociedades cooperativas, a través de sus estatutos o de acuerdos de la Asamblea General, en todas las materias en que así se consideró conveniente; y, dos, facilitar el desarrollo de la empresa en que consista el objeto social de cada sociedad cooperativa mediante una configuración adecuada de la estructura y funcionamiento de tales entes.

Con el objetivo de que las organizaciones representativas del sector cooperativo participasen en la acción pública de la Junta de Extremadura en materia de economía social, se crea el Consejo Superior del Cooperativismo de Extremadura, como órgano administrativo colegiado asesor de la Administración Autónoma de Extremadura en la formulación de la política en materia de sociedades cooperativas y laborales, y al que se le atribuirán funciones arbitrales. Su composición y régimen de funcionamiento está regulado por el Decreto 130/1998, de 17 de noviembre, reformado por el Decreto 246/2000, de 5 de diciembre.

Pero el punto de partida, en lo relativo al arbitraje cooperativo ante el Consejo Superior, son los artículos 186, 166 y 167 de la Ley 2/1998. El artículo 186 se encarga de establecer las funciones de esta institución, entre las que se encuentran velar por la exacta adecuación del fondo de educación y promoción a los fines para los que fue creado; facilitar la planificación y colaborar en la ejecución de los programas de desarrollo y fomento del cooperativismo, así como en los de formación y educación cooperativa; ser oído en cuantos expedientes se tramiten en materia de descalificación de sociedades cooperativas; e intervenir, mediante las instituciones de la mediación, la conciliación y el arbitraje, en los conflictos colectivos y en los conflictos individuales a que se refieren los artículos 166 y 167 de esta Ley; así como las demás que deriven de Ley y del reglamento que lo regula.

Por su parte, los artículos 166 y 167 disponen que los conflictos que surjan entre varios socios y/o asociados y la sociedad cooperativa a que pertenecen, entre varias sociedades cooperativas, entre la sociedad cooperativa o sociedades cooperativas y la federación en que se integren, así como entre las federaciones de sociedades cooperativas, 
podrán ser sometidos a la consideración del Consejo Superior del Cooperativismo de Extremadura, mediante las instituciones de la mediación, la conciliación y el arbitraje, consistiendo el arbitraje en la adopción de un laudo de obligado cumplimiento. Al mismo tiempo, los conflictos que surjan entre algún socio y la sociedad cooperativa a la que pertenece así como entre ésta y la federación en la que se integra, también podrán ser sometidos a la consideración del Consejo Superior de Cooperativas de Extremadura mediante las instituciones de la mediación, de la conciliación y el arbitraje voluntario.

De esta regulación legal resaltar básicamente dos cuestiones: la innovadora distinción entre los conflictos individuales y colectivos que surjan en el seno de las relaciones cooperativas, remitiéndose al Reglamento de desarrollo para tratar de manera diferente la regulación de la legitimación de las partes según se trate de conflicto individual o colectivo; y, asimismo, la especial mención a los distintos medios de acometer un eventual conflicto, citando como tales -en todas las ocasiones- la mediación, la conciliación y el arbitraje.

En fecha de 17 de noviembre de 1998 se aprueba el Reglamento de Organización y Funcionamiento del Consejo Superior del Cooperativismo de Extremadura, Decreto 130/1998, el cual, transcribiendo el artículo 186.1.b) de la Ley 2/1998, vuelve a reconocer como función del citado órgano colegiado la de intervenir, mediante las instituciones de la mediación, la conciliación y el arbitraje, en los conflictos colectivos y en los conflictos individuales de naturaleza cooperativa. Asimismo, dispone que los conflictos deben recaer sobre materias de libre disposición por las partes y que la sumisión debe estar prevista en los estatutos sociales, reglamento interno o cláusula compromisoria.

En cumplimiento de lo dispuesto en los apartados segundos de los artículos 166 y 167 de la Ley 2/1998 se aprueba, en fecha de 5 de diciembre de 2000, el Reglamento de Arbitraje, Conciliación y Mediación Cooperativos, Decreto 245/2000. El Reglamento trata de establecer el cauce formal por el que debe discurrir la resolución de los conflictos cooperativos, constituyendo el régimen más singular y desarrollado de solución extrajudicial de conflictos cooperativos del ordenamiento jurídico español. Con él se persiguen dos finalidades básicas: por una parte, ofrecer una alternativa ágil y rápida a las sociedades cooperativas extremeñas y a los cooperativistas para evitar el proceso judicial en la resolución de los conflictos que surjan y, por otra, asumir la financiación de este sistema de solución extrajudicial 
con presupuestos de la Consejería de Trabajo para que a la agilidad y rapidez antes referida se una la gratuidad del sistema.

Entrando en la regulación que sobre el arbitraje cooperativo realiza el Reglamento de Arbitraje, Conciliación y Mediación Cooperativos, señalar que la intervención del Consejo se ejerce a través de una Comisión de Trabajo denominada Comisión de Conflictos Cooperativos. Esta Comisión esta compuesta por tres miembros designados por el Pleno del Consejo y nombrados por su Presidente por un período de cuatro años. La Comisión elige por unanimidad, de entre sus miembros, un Presidente y un Secretario; y adopta sus acuerdos por mayoría. La Comisión de Conflictos Cooperativos presta en todo momento su asesoramiento y su asistencia en la tramitación de los procedimientos de arbitraje, de conciliación y de mediación, con el objeto de procurar que los árbitros, los conciliadores y los mediadores cumplan adecuadamente su función. Por su parte, éste es el órgano que se encarga de resolver cualquier duda que se suscite en relación con la aplicación o interpretación del presente Reglamento, de oficio o cuando lo soliciten los árbitros, los conciliadores o los mediadores.

Según el Reglamento, pueden ser sometidos al arbitraje -así como a la conciliación o a la mediación - los conflictos que se originen entre sociedades cooperativas; entre socios o asociados y la sociedad cooperativa a la que pertenezcan; entre socios y/o asociados de la misma o de distinta sociedad; entre uniones, federaciones y asociaciones de cooperativas, y entre éstas y los socios que las forman; y entre una sociedad cooperativa de segundo o ulterior grado y los socios de las sociedades cooperativas de base, y entre las uniones, federaciones y asociaciones y los socios de las sociedades cooperativas miembros. Teniendo presente que sólo podrán ser sometidas a la Comisión de Conflictos Cooperativos aquellas cuestiones litigiosas que versen sobre materias de libre disposición por las partes conforme a Derecho y que se deriven de la actividad cooperativa o asociativa.

El artículo 4 del Reglamento se encarga de definir las distintas clases de conflictos existentes. El precepto dispone que se entiende por conflicto individual aquél en el que la solución del mismo sólo afecta a las partes en conflicto; y por conflicto colectivo cuando la solución de éste tenga eficacia general. En este caso los afectados por la solución, a falta de cumplimiento voluntario por el obligado a ello, podrán alegarla aunque no hayan sido parte en el conflicto colectivo; estando legitimados para promover procedimientos de arbitraje sobre conflictos 
colectivos la propia sociedad cooperativa afectada o un cinco por ciento de sus socios o asociados y la unión, federación o asociación afectada o un cinco por ciento de sus socios -asimismo, estarán legitimados, en todo caso, las uniones, federaciones y asociaciones y las sociedades cooperativas de segundo o ulterior grado en relación con los miembros de las mismas-.

Los procedimientos regulados en el Reglamento se fundamentan en los principios de audiencia, contradicción, economía procesal, igualdad entre las partes y gratuidad. Junto a esta regla general, en los artículos 6 a 8 del Decreto, se recogen otras normas comunes a los tres procedimientos relativas al lugar de celebración de los actos, las notificaciones y comunicaciones, y el cómputo de plazos.

En cuanto a los árbitros, éstos serán nombrados por la Comisión de Conflictos Cooperativos. Si hay acuerdo entre las partes, la Comisión nombrará a los propuestos por éstas, pero, en caso contrario, éstos serán designados por orden de reparto de entre una lista cerrada de árbitros que aprueba el Pleno del Consejo ${ }^{67}$.

El Reglamento, consciente en todo momento del principio de jerarquía normativa, establece que para que el arbitraje sea válido deberá ajustarse a las prescripciones de la legislación del Estado sobre arbitraje. La sumisión al arbitraje de la Comisión de Conflictos Cooperativos se producirá siempre que exista convenio arbitral principal o accesorio y, en particular, cuando las partes estén obligadas a ello a tenor de los estatutos sociales o reglamento de régimen interno de la entidad de que se trate; cuando exista convenio arbitral entre las partes por el cual someten al arbitraje los conflictos que pudieran surgir entre los mismos, si cualquiera de ellas se dirige a la comisión de conflictos cooperativos y solicita su intervención en los términos previstos en el reglamento; y/o cuando surgidas discrepancias entre partes, exista acuerdo de todas ellas de someterse al arbitraje de la comisión de conflictos cooperativos y, especialmente, cuando intentada la conciliación o la mediación ésta hubiese finalizado sin avenencia, y las partes decidan, de mutuo acuerdo, someter la cuestión al arbitraje de la

67 Entre licenciados en Derecho, Graduados Sociales o Diplomados en Relaciones Laborales, Economistas, Ingenieros, titulados equivalentes o personas que, sin contar con las mencionadas titulaciones, tengan experiencia suficiente en la materia y reconocido prestigio en el sector. No siendo la condición de miembro de la Comisión de Conflictos Cooperativos obstáculo para el nombramiento como árbitro. 
comisión. La sumisión al arbitraje de la Comisión de Conflictos Cooperativos implica que tanto la administración del arbitraje como el nombramiento de los árbitros corresponde a la misma en la forma prevista en el Reglamento.

Finalmente señalar que las costas del arbitraje, que incluirán los honorarios y gastos debidamente justificados de los árbitros, los gastos que origine la protocolización notarial del laudo y su aclaración, los derivados de notificaciones y los que origine la práctica de las pruebas, corren a cargo de la Consejería de Trabajo.

\section{VI.5. Galicia}

En el Título 4 de la Ley 5/1998, de18 de diciembre, de Cooperativas, rubricado "De las asociaciones y representación cooperativa», se regulan —en dos Capítulos- el asociacionismo cooperativo y el Consejo Gallego de Cooperativas. Para ordenar, clarificar y potenciar la representatividad de las sociedades cooperativas se configura en la Ley un diseño del asociacionismo cooperativo de estructura piramidal en su triple manifestación de uniones, federaciones y confederaciones, a fin de garantizar la esencia del movimiento cooperativo y ayudar a su consolidación, respetando en todo caso la autonomía y la libertad de asociación. Por su parte, se crea el Consejo Gallego de Cooperativas como máximo órgano de promoción y difusión del cooperativismo en la Comunidad Autónoma. Se trata de una institución con funciones de carácter consultivo y asesor de las Administraciones Públicas en esta materia, diseñado como un órgano colegiado en el cual participan las diferentes Administraciones, las instituciones y el movimiento cooperativo, todos ellos interesados en el fomento, la promoción y la difusión del cooperativismo. Además de las funciones de carácter consultivo, se le atribuyen otras importantes como el nombramiento de liquidadores en determinados supuestos, la planificación y gestión de los fondos de formación y promoción de las cooperativas que los transfieran voluntariamente $u$ obligatoriamente si no los han gestionado en el plazo legalmente previsto, y - como no- el arbitraje en cuestiones litigiosas cooperativas. Así, la Ley 5/1998, de 18 de diciembre, de Cooperativas de Galicia, dedica sus artículos 135 y 136 a la creación del Consejo Gallego de Cooperativas, estableciendo su naturaleza, funciones y composición. En lo relativo al arbitraje, concretamente en el artículo 135.2.f), se le atribuye al Consejo la competencia para "conciliar y ejercer el arbitraje en las cuestiones litigiosas que 
se planteen entre cooperativas, entre éstas y sus socios, o en el seno de las mismas entre sus socios, cuando ambas partes lo soliciten o bien estén obligadas a ello en razón a lo establecido en sus estatutos».

La Disposición Final tercera de la Ley facultó a la Xunta de Galicia para que, en el plazo de dieciocho meses y por propuesta del Consejero competente en materia de trabajo, dictase las normas necesarias para el desarrollo de la institución del Consejo Gallego de Cooperati$v^{2} s^{68}$. Fruto de dicha obligación legal, en fecha de 18 de enero de 2001, se aprueba el Decreto 25/2001 del Consejo Gallego del Cooperativismo. En este Decreto, a diferencia de lo que habitualmente ocurre con las normas que regulan los Consejos Autonómicos del Cooperativismo, únicamente se recoge de nuevo la simple mención a la competencia del Consejo para conciliar y ejercer el arbitraje —artículo 3.1.f)—.

Ante el nulo desarrollo que existía respecto a la función arbitral del Consejo se realizó un dictamen del Consejo Consultivo de Galicia, de veintitrés de septiembre de dos mil cuatro, en el que se recomendaba la adopción de un Reglamento relativo a los procedimientos de conciliación y arbitraje cooperativo. En vista del mismo, a propuesta de la Conselleira de Asuntos Sociales, Empleo y Relaciones Laborales, y previa deliberación del Consejo de la Xunta de Galicia en su reunión del día 14 de octubre de 2004, se procedió a aprobar el Decreto $248 / 2004$, de 14 de octubre, sobre los procedimientos de conciliación y arbitraje cooperativo.

Con la aprobación de este Decreto se trata de establecer el cauce formal de los procedimientos de conciliación y arbitraje cooperativo con el fin de atender adecuadamente las funciones que en estas materias corresponden al Consejo Gallego de Cooperativas mediante la oferta de una alternativa ágil para evitar el proceso judicial en la resolución de los conflictos que surjan.

El Decreto tiene por objeto el desarrollo de la organización administrativa y la regulación del régimen de gestión de los procedimientos

68 Dada la especial importancia del Consejo como máximo órgano de promoción y difusión del cooperativismo en Galicia, así como su papel de vía de participación institucional del movimiento cooperativo y la conveniencia de que los propios representantes de las cooperativas participen en la propia aplicación y desarrollo de la normativa autonómica en la materia, resulta necesario complementar la Ley de Cooperativas de Galicia en los aspectos que posibiliten la constitución del Consejo Gallego de Cooperativas. 
de conciliación y arbitraje cooperativo que son competencia del Consejo Gallego de Cooperativas. Son cuestiones susceptibles de conciliación y arbitraje, aquellas cuyo objeto sean cuestiones litigiosas derivadas de la actividad cooperativa sobre materias de libre disposición conforme a derecho y que se planteen entre cooperativas, entre cooperativas y sus socios, y entre los socios de una cooperativa; siendo necesario que se trate de cooperativas inscritas en el Registro de Cooperativas de Galicia.

Para intervenir como parte contendiente en estos procedimientos es necesario acreditar estar en posesión de la condición de socio de una cooperativa gallega o haber perdido dicha condición por los hechos que se someten a conciliación o arbitraje, o la constitución como sociedad cooperativa gallega o como asociación de éstas, lo que se debe acreditar de conformidad a lo dispuesto en la Ley 5/1998, de 18 de diciembre, de Cooperativas de Galicia ${ }^{69}$.

Al igual que en el resto de legislaciones autonómicas, el Reglamento regula una serie de cuestiones generales y comunes a todo proceso, como los principios de contradicción, economía procesal y agilidad que inspiran los procedimientos, el cómputo de plazos, los honorarios y gastos, etcétera. El Reglamento obliga al Consejo a la creación de un Registro de conciliadores y árbitros. Así, tras las oportunas consultas a los medios e instituciones relacionados con el cooperativismo, el Consejo Gallego de Cooperativas debe confeccionar un registro de personas físicas que estén en el pleno ejercicio de sus derechos civiles y que estime idóneas para actuar como conciliadores y árbitros. Para ello deben tenerse presente dos reglas: que cuando la cuestión litigiosa sea sometida a arbitraje de derecho, los árbitros serán abogados en ejercicio; y que las propuestas, designaciones y nombramientos de los conciliadores y árbitros que hayan de intervenir en los procedimientos se harán sobre personas comprendidas en el registro.

En el seno del Consejo Gallego de Cooperativas se crea la Comisión de Conciliación y Arbitraje Cooperativo, como órgano sin personalidad jurídica al que se le encomienda la función de gestionar y ejercer las funciones de conciliación y arbitraje cooperativo que tiene atribuidas el Consejo. Sus funciones son proceder al nombramiento

69 Las partes podrán actuar por sí mismas o por medio de representante. El poder de representación podrá otorgarse ante notario o «apud acta» ante el secretario de la Comisión de Conciliación y Arbitraje. 
de conciliadores y árbitros; resolver las cuestiones relativas a la recusación y sustitución de aquéllos; resolver las cuestiones que se planteen sobre la interpretación de las disposiciones reglamentarias - con efectos sólo aplicables al caso particular del que se trate-; prestar asistencia y apoyo en la tramitación de los procedimientos; velar por el debido cumplimiento de las disposiciones que rigen los procedimientos de conciliación y arbitraje cooperativo; prestar al Consejo el asesoramiento y ayuda que le solicite sobre materias relacionadas con sus funciones de conciliación y arbitraje cooperativo; conocer y decidir sobre aquellas cuestiones que sea competente en virtud de disposiciones de rango legal, o en virtud de un acuerdo del Consejo; y llevar un registro de las resoluciones de conciliaciones y de los laudos que recaigan y se dicten en los procedimientos.

La Comisión de Conciliación y Arbitraje Cooperativo esta compuesta por tres miembros - a saber, Presidente, Vicepresidente y Secretario-, sus acuerdos se adoptan por mayoría, y su régimen de funcionamiento es el previsto en la Ley para los órganos colegiados, dirimiendo el voto del presidente los empates que se produzcan. El Presidente y el Vicepresidente son designados por el Pleno del Consejo Gallego de Cooperativas de entre sus miembros y nombrados por su Presidente por un período de cuatro años - pudiendo ser reelegidos $^{70}$ _. Por su parte, el Secretario de la Comisión es el Secretario del Consejo.

Las funciones del Presidente son: ostentar la representación de la comisión; proponer los pagos derivados de las funciones de conciliación y arbitraje; así como elaborar el orden del día y convocar y presidir las reuniones de la Comisión. El Vicepresidente ejerce las funciones del presidente en los casos de vacante, ausencia o incapacidad de éste. Y las funciones del Secretario son: instruir los procedimientos de conciliación y de arbitraje que se inicien ante la Comisión —hasta la puesta a disposición de los conciliadores o de los árbitros-; hacer las comunicaciones y notificaciones que sean precisas a todos los intervinientes en los procedimientos; prestar asistencia técnica a los conciliadores o árbitros que la soliciten; ordenar, custodiar y archivar la documentación correspondiente a los procedimientos; expedir certificaciones de los documentos confiados a su custodia, con el visto bue-

70 Del mismo modo serán designados y nombrados sus sustitutos, en el caso de producirse alguna vacante por el tiempo que restara de mandato. 
no del presidente; y elaborar la memoria anual que la Comisión de Conciliación y Arbitraje elevará al Consejo Gallego de Cooperativas, en la que se informe especialmente sobre el estado de los procedimientos tramitados y, en su caso, resueltos durante el período de que se trate.

Finalmente, en cuanto al arbitraje cooperativo, el Reglamento establece que las cuestiones que pueden ser sometidas a arbitraje lo serán cuando las partes estén obligadas a ello en virtud de una norma legal, en razón de lo establecido en los Estatutos sociales de la correspondiente cooperativa, y/o en el caso de tener firmado las partes un convenio arbitral. No obstante, cuando el litigio se plantee entre cooperativas, la obligatoriedad del sometimiento a arbitraje basada en previsión estatutaria tiene que estar recogida en los estatutos de cada cooperativa contendiente. Asimismo, las partes pueden someter la cuestión litigiosa al procedimiento de arbitraje cuando así lo acuerden entre ellas mediante la suscripción del correspondiente convenio arbitral o en el supuesto previsto en el artículo 19.5 del Decreto ${ }^{71 .}$

\section{VI.6. El procedimiento arbitral: Cuestiones comunes}

En el presente apartado se pretende hacer una especie de resumen de los principales pasos comunes a todo procedimiento arbitral cooperativo, por lo que debe tenerse en cuenta que, por ejemplo, los plazos aquí establecidos varían dependiendo de la comunidad autónoma que se trate.

Para que el procedimiento arbitral se ponga en marcha es necesario que una de las partes requiera a la otra - u otras - para someter la controversia al arbitraje pactado, habiendo recibido ésta dicho requerimiento, artículo 27 Ley 60/2003. La solicitud de arbitraje se lleva a cabo mediante un escrito dirigido a la Institución autonómica competente, debiendo contener, por regla general: el nombre y apellidos, si se trata de persona física, o denominación o razón social, si se trata de persona jurídica, así como el domicilio a efectos del primer emplazamiento del demandando; referencia, en su caso, al convenio arbitral principal o accesorio, adjuntando copia del mismo; una sucinta descripción de la relación jurídica de la que se derive la cuestión contro-

71 «En el caso de que la propuesta del conciliador no sea aceptada por las partes, éstas pueden expresar su voluntad de someter la cuestión litigiosa al procedimiento de arbitraje». 
vertida que se somete a arbitraje; exposición de las pretensiones del demandante, indicando los hechos y los fundamentos de derecho en que base las mismas; y número de árbitros que se solicitan, pudiéndose indicar uno o varios, en todo caso impar, y el nombre, apellidos y domicilio de los propuestos.

Si el escrito de solicitud omite algunos de los requisitos enunciados, o si alguno de ellos fuese incompleto o confuso, suele concederse un plazo de diez días para la subsanación de tales defectos. Si la parte no lo hiciere, y siempre y cuando tales omisiones imposibiliten la continuación del procedimiento, se tiene la solicitud por desistida, previa resolución dictada al efecto por la institución competente.

Si se cumplen los requisitos suele darse traslado de la solicitud a la parte demandada para que, en el plazo de diez días, indique su conformidad o no con el número y con la identidad de los árbitros propuestos por el demandante, y formule, si es el caso, contestación - pudiendo el demandado en este trámite oponerse al arbitraje- - Si la parte demandada ni se opusiere al arbitraje ni tampoco contestara a la demandada en el plazo de dichos quince días, el procedimiento continua considerando a la misma en rebeldía, en tanto que la inactividad de las partes no impide que se dicte el laudo arbitral ni le priva de eficacia.

Los árbitros, tras su aceptación, convocan a las partes a una reunión para la concreción de la cuestión sometida a arbitraje. Por propia iniciativa o a instancia de parte los árbitros pueden abrir un período de pruebas, que será de diez días, decidiendo éstos sobre la realización o no de las pruebas propuestas. En toda práctica de prueba las partes son citadas y pueden intervenir. Por su parte los árbitros podrán solicitar, para su práctica, el auxilio judicial. El período para practicar las pruebas es de diez días, pudiendo los árbitros, si lo estiman conveniente, prorrogarlo en el caso de que sea imposible practicarlas en dicho plazo.

Practicadas las pruebas, en su caso, los árbitros citan a las partes para la celebración de una vista, que tiene lugar en el plazo máximo de cinco días, en la que éstas presentan sus conclusiones. Si se han practicado pruebas los árbitros trasladarán a las partes el resultado de las mismas al hacer la citación. Excepcionalmente, y una vez realizada la vista, los árbitros pueden ordenar la realización de aquellas pruebas que estimen necesarias, motivando las razones por las que deban practicarse. En caso de llevarse a cabo las mismas, se conce- 
derá a las partes un nuevo plazo de diez días para presentar nuevas conclusiones.

El procedimiento finaliza con la emisión del laudo, que debe dictarse en el plazo máximo de veinte días desde la presentación de las conclusiones y dentro del plazo máximo de seis meses establecido por la legislación arbitral general. El contenido del laudo se decide por mayoría de votos y se dicta por escrito, debiendo contener tanto las circunstancias que exige el artículo 37 de la Ley Arbitral, como el pronunciamiento sobre las costas, que incluirá los gastos que originen la protocolización notarial del laudo y su aclaración, los gastos derivados de notificaciones y los que se originen por la práctica de pruebas. Finalmente se firmará por todos los árbitros, pudiéndose hacer constar las opiniones discrepantes, y se acordará su notificación fehaciente a las partes, momento a partir del cual empieza a contar el plazo para presentar recursos, el de anulación, transcurrido el cual el laudo alcanzará firmeza y con ella los efectos típicos del mismo: cosa juzgada y ejecutoriedad. En este sentido, el laudo arbitral firme produce efectos idénticos al de la cosa juzgada y contra éste sólo cabe recurso de revisión, de acuerdo con lo que establece la legislación procesal para las sentencias judiciales firmes.

\section{Algunas reflexiones sobre la conciliación cooperativa en la legislación autonómica}

La conciliación es una vía de resolución de conflictos, en principio, alternativa a la jurisdicción, consistente en un actividad desarrollada por sujetos entre los que existe un conflicto jurídico de intereses -en nuestro caso cooperativo - en presencia de un tercero -en nuestro caso, habitualmente, un Consejo Superior del Cooperativismo-. De dicha actividad se pretende la resolución del conflicto mediante la obtención de un acuerdo entre los propios sujetos implicados en el mismo.

El principal problema que presenta la regulación de la conciliación cooperativa en algunas legislaciones cooperativas autonómicas está, al igual que ocurría en el arbitraje cooperativo, en que el legislador autonómico se extralimita en sus competencias y establece reglas que violan el principio de jerarquía normativa, al ir en contra de la legislación estatal en cuestiones que deben quedar sometidas a las directrices marcadas por ésta. Se trata, en concreto, de los distintos efectos 
que la legislación estatal y alguna legislación cooperativa autonómica confieren al acuerdo de conciliación.

Según las normas estatales, que son las únicas aplicables, el acuerdo de conciliación tiene la eficacia de una mera transacción extrajudicial, por lo que para solicitar su ejecución, primero, deberá se utilizado como medio de prueba en un proceso judicial declarativo del que se derive una sentencia que constituya título ejecutivo. Por ejemplo, el acuerdo de conciliación fruto de una conciliación judicial preprocesal, regulada en el artículo 476 de la Ley de Enjuiciamiento Civil de 1881, actualmente en vigor por efecto de la Disposición Derogatoria única - apartado $1 .^{\circ}$, punto $2 .^{\circ}$ - , confiere a dicho acuerdo, en el apartado segundo del precepto, valor y eficacia de un convenio consignado en documento público y solemne. Ello supone, en virtud del artículo 517 de la Ley $1 / 2000$, de 7 de enero, de Enjuiciamiento civil, que no constituye título ejecutivo, en tanto que el precepto únicamente confiere dicha condición, dentro de lo que son los documentos públicos y solemnes, a los notariales -aparatado 4. ${ }^{\circ-}$. A la misma conclusión se puede llegar si atendemos a la actual Ley Arbitral, en cuyo artículo 36 se establece que "1. Si durante las actuaciones arbitrales las partes llegan a un acuerdo que ponga fin total o parcialmente a la controversia, los árbitros darán por terminadas las actuaciones con respecto a los puntos acordados $y$, si ambas partes lo solicitan y los árbitros no aprecian motivo para oponerse, harán constar ese acuerdo en forma de laudo en los términos convenidos por las partes. 2. El laudo se dictará con arreglo a lo dispuesto en el artículo siguiente y tendrá la misma eficacia que cualquier otro laudo dictado sobre el fondo del litigio». Una interpretación a "contrario sensu» nos conduce a afirmar que el acuerdo entre las partes que no se materialice en un laudo dictado con arreglo a lo dispuesto en la Ley Arbitral no tendrá la eficacia que ésta le reconoce al mismo, y que por tanto no será ejecutable ante los Tribunales.

El problema, pues, surge cuando la legislación cooperativa autonómica confiere al acuerdo de conciliación el valor de título ejecutable, como ocurre en el caso del artículo 7.6 del Reglamento Catalán de Conciliación ante el Consejo Superior de la Cooperación, Decreto 118/1993, de 6 de abril; o el artículo 123.1.a) de la Ley Valenciana 8/2003, de 24 de marzo, que establece que «la conciliación previa, de carácter voluntario, al ejercicio de acciones ante los tribunales... será la prevista en el reglamento del Consejo, e incluirá el reconocimiento de que las certificaciones de avenencia son título suficiente para obtener la ejecución de lo acordado». 
Este problema que hemos apuntado no ha llegado a los Tribunales, pero si ello se produce, entendemos que el Tribunal deberá denegar el carácter ejecutivo del acuerdo de conciliación, porque por mucho que en la legislación se autorice la ejecución judicial del certificado de conciliación, lo cierto es que, atendiendo a la legislación procesal estatal, que es la única aplicable, esta transacción extrajudicial debe tener una mera eficacia contractual, que permitirá ejercitar las acciones civiles derivadas de su incumplimiento, pero nada más ${ }^{72}$.

Ahora bien, también es cierto que algunas legislaciones autonómicas mantienen una posición acertada al respecto. Así, el artículo 37 del Reglamento Extremeño de Arbitraje, Mediación y Conciliación Cooperativos establece que «aceptada la propuesta — de conciliaciónésta tendrá la eficacia jurídica derivada de los contratos»; y el artículo 176.1.a) de la Ley Andaluza 2/1999, de 31 de marzo, dispone que «la conciliación previa, de carácter voluntario, al ejercicio de acciones ante los Tribunales... tendrá los efectos que determine la legislación estatal reguladora del arbitraje de derecho privado».

\section{Bibliografía}

Botana Agra, M. «Acerca de la sumisión a arbitraje de la impugnación de acuerdos de sociedades anónimas», Derecho de los negocios, 1999.

BUITRON ANDRADE, «Evolución de la figura del Consejo Superior de Cooperativas en la legislación cooperativa española» en Anuario de Estudios Cooperativos, 1999.

CAMpo Villegas, E. «El arbitraje en las sociedades mercantiles», RJC, 1998.

CARAZO LiéBANA, M.J. "La aplicación del arbitraje a la impugnación de acuerdos societarios en las sociedades de capital», en RDM, 1998.

COHEN. "Arbitrage et société», Bibliothèque de Droit Privé, 1992.

CORDÓn MOREno, F. El arbitraje en el Derecho Español: interno e internacional, Aranzadi, 1995.

Cucarella Galiana, L.A. El procedimiento arbitral (Ley 60/2003, de 23 de diciembre, de Arbitraje), Editorial Publicaciones del Real Colegio de España, Bolonia, 2004.

FeRnÁNDEZ DEL POZO, «Publicidad mercantil registral del procedimiento arbitral», RCDI, núm. 612, 1992.

Fernández del Pozo, L. "Sobre la arbitrabilidad de las controversias relativas a la impugnación de acuerdos sociales», RGD, 1995.

72 En igual sentido, Trujılo Díez, I.J. El arbitraje..., cit., pág. 170. 
González García, «La llamada cláusula arbitral», Món Jurídic, núm. 121, 1995.

Martí Miravalls, J. «El arbitraje cooperativo. El caso valenciano» en Revista Jurídica de Economía Social y Cooperativa, núm. 14, 2003.

Merino Hernández, S. Administración Pública y sociedades cooperativas: el caso vasco, 1999.

Merino Hernández, S. Manual de Arbitraje Cooperativo Vasco, CSCE, 2001.

MuÑoz PLANAS, "Algunos problemas del arbitraje en materia de sociedades mercantiles», Estudios de Derecho Mercantil en homenaje a RODRIGO URIA, 1978.

Muñoz VIDAL, A. El arbitraje cooperativo, Caja rural provincial de Murcia, 1978.

Ortells Ramos, M. Derecho procesal civil, Aranzadi, 2000.

PANTALEÓN, F. "Análisis crítico del reglamento arbitral del Consejo Superior de Cooperativas de Euskadi», IV Encuentros Cooperativos de la Universidad del País Vasco, 1991.

Picó I JunoyNÁzquez AlbeRT, «El arbitraje en la impugnación de acuerdos sociales», Derecho de Sociedades, 1999.

POLO, A. «Misión y sentido de la nueva Ley de Cooperación», RDP, 1942.

Polo, E. «Introducción y ámbito de eficacia de la cláusula compromisoria en las sociedades mercantiles», en Butlletí TAB núm. 4, 1992.

SENENT VIDAL, M.J. La impugnació dels acords social en la cooperativa, Athenea, 2003.

Suso VIDAL, J.M. "Análisis del anteproyecto de Ley Vasca de Arbitraje Cooperativo», en I Congreso de Derecho Vasco de Arbitraje, Instituto Vasco de Derecho Procesal, 1988.

TRUIILLO DíEZ, I.J. «El arbitraje cooperativo. Régimen legal y otras cuestiones», en Estudios sobre economía social y derecho cooperativo, 2000.

VICENT CHULIÁ, F. "Análisis crítico del nuevo Reglamento de Cooperación», RDM, núm. 125, 1972.

VICENT CHULIÁ, F. «El arbitraje en materia de impugnación de acuerdos sociales» $R G D$, núms. 646-647, 1998.

VICENT CHULIÁ, F. «La Asamblea General de la Cooperativa», RJC, 1978.

VICENT ChULIÁ, F. Compendio Crítico de Derecho Mercantil, Tirant lo Blanch, 1981.

VICENT ChULIÁ, F. «Arbitraje de impugnación de acuerdos sociales. Acto final», Anuario de justicia alternativa, núm. 1, 2001.

Villalobos/Delibes/Alonso, Comunidades de bienes, cooperativas y otras formas de empresas, Consejo General del Notariado, 1996. 